\title{
Object file continuity and the auditory attentional blink
}

\author{
Dawei Shen And Todd A. Mondor \\ University of Manitoba, Winnipeg, Manitoba, Canada
}

\begin{abstract}
Three experiments were designed to investigate the causes of the auditory attentional blink (AB). Experiments $1 \mathrm{~A}$ and $1 \mathrm{~B}$ revealed that there was a larger auditory $\mathrm{AB}$ when the target and the distractors were different in two attributes than when they were different in only one attribute. Experiments $2 \mathrm{~A}$ and $2 \mathrm{~B}$ showed that for pure-tone distractor sequences, there were small auditory $\mathrm{AB}$ deficits when both the target and the probe were different from the distractors in two attributes or in one attribute; however, for pulse distractor sequences, there was a large auditory $\mathrm{AB}$ when both the target and the probe were different from the distractors in one attribute, but not when they were different in two attributes. Experiments $3 \mathrm{~A}$ and $3 \mathrm{~B}$ revealed that regardless of the relationship of the target to the subsequent distractors, a large $\mathrm{AB}$ was generated if it was the first sound in a sequence. Moreover, only a very small $\mathrm{AB}$ was apparent when the distractors following the probe were replaced by silence. These results indicated that the auditory $\mathrm{AB}$ is affected by both the requirement of creating and consolidating a new object file for the target and the overwriting of the probe by the distractors following it.
\end{abstract}

The attentional blink $(\mathrm{AB})$ refers to a phenomenon that may arise when critical items, a target and a probe, are present in a rapid serial visual presentation (RSVP) stream. Under these conditions, correct identification of the target often results in a deficit of several hundred milliseconds in processing the subsequently presented probe (Raymond, Shapiro, \& Arnell, 1992). Most theorists regard the AB as providing important information regarding attention allocation in the temporal domain.

The stimulus onset asynchrony (SOA) between two successive items in an RSVP stream is usually about $100 \mathrm{msec}$. Normally, the number of the items in one stream varies from 12 (see, e.g., Broadbent \& Broadbent, 1987) to 25 (see, e.g., Kawahara, Di Lollo, \& Enns, 2001). In general, in an $\mathrm{AB}$ paradigm, performance is examined in both an experimental condition and a control condition. In the experimental condition, participants are required to identify or detect both the target and the probe. In one version of the control condition, participants are instructed to ignore the target, although it is present. In another version, participants are instructed to detect or identify the target, but it is absent. The advantage of the former is that it permits an evaluation of the influence of sensory masking on the detection or identification of the probe by the target (see, e.g., Raymond et al., 1992); the advantage of the latter is that it eliminates the influence of involuntary attentional capture by the target on the detection or identification of the probe (see, e.g., Jiang \& Chun, 2001). Regardless of the particular type of control condition used, the accuracy of probe perception is typically higher in the control condition than in the experimental condition, and this difference decreases as the time between the target and the probe increases. This AB persists for approximately 400 to $500 \mathrm{msec}$ (see, e.g., Broadbent \& Broadbent, 1987).

To date, quite a large number of studies have been conducted to examine the visual $\mathrm{AB}$ phenomenon using various kinds of materials, including dot patterns (e.g., Giesbrecht \& Di Lollo, 1998), keyboard symbols (e.g., Chun \& Potter, 1995; Potter, Staub, \& O'Connor, 2002), letters (e.g., Isaak, Shapiro, \& Martin, 1999; Jiang \& Chun, 2001; Jolicœur, 1998; Jolicœur \& Dell'Acqua, 1998; Raymond et al., 1992; Raymond, Shapiro, \& Arnell, 1995; Seiffert \& Di Lollo, 1997; Shapiro, Raymond, \& Arnell, 1994), letters and digits (e.g., Brehaut, Enns, \& Di Lollo, 1999; Chun \& Potter, 1995; Duncan, Ward, \& Shapiro, 1994; Giesbrecht \& Di Lollo, 1998; Kawahara et al., 2001; Kawahara, Zuvic, Enns, \& Di Lollo, 2003; Nieuwenstein, Chun, van der Lubbe, \& Hooge, 2005; Ward, Duncan, \& Shapiro, 1996), line segments (e.g., Kawahara et al., 2001; Kawahara et al., 2003), nature scene images (Evans \& Treisman, 2005), object images (e.g., Kellie \& Shapiro, 2004), shapes (e.g., Raymond, 2003), words (e.g., Broadbent \& Broadbent, 1987; Olson, Chun, \& Anderson, 2001; Potter et al., 2002), and so on.

In studies of the visual $\mathrm{AB}$, one of the factors that has been studied most often is related to the effect of distractors, including the local effects of the distractor items immediately following the target and the probe and a global effect of all distractor items in a sequence (e.g., Chun \& Potter, 1995). For example, some researchers (e.g., Chun \& Potter, 1995; Raymond et al., 1992, 1995; Seiffert \& Di Lollo, 1997) have found that the item immediately following the

D. Shen, dshen@rotman-baycrest.on.ca 
target - in terms of serial position, this item is typically referred to as the +1 item - has an important influence on the visual $A B$. Specifically, the magnitude of the visual $A B$ has been found to increase as the similarity of the target and +1 item increases (e.g., Chun \& Potter, 1995; Raymond et al., 1995). Furthermore, the visual AB is eliminated or much reduced in size when the +1 item is replaced by a blank of equivalent duration (e.g., Chun \& Potter, 1995; Raymond et al., 1992; Seiffert \& Di Lollo, 1997).

The distractors following the probe have also been found to be an important determinant of the visual AB. Chun and Potter (1995), for example, found that the magnitude of the visual $A B$ increased as the similarity of the postprobe distractor to the probe increased. Other researchers have reported that the visual $\mathrm{AB}$ is nearly eliminated when the distractors following the probe are all deleted (e.g., Giesbrecht \& Di Lollo, 1998; Kawahara et al., 2001; Kawahara et al., 2003). There also appears to be a global effect of all of the distractor items in a sequence on the visual AB. For example, Chun and Potter (1995) found that the magnitude of the visual $\mathrm{AB}$ increased as the discriminability of the target and probe within a sequence was reduced.

The visual AB also appears to be influenced by factors such as the relationship between the target and the probe (see, e.g., Broadbent \& Broadbent, 1987; Shapiro et al., 1994) and target processing difficulty (see, e.g., Jolicœur, 1998; Olson et al., 2001). For example, Shapiro et al. (1994) found that there was no significant $\mathrm{AB}$ when the target (a gap in the RSVP stream) and the probe (a letter) were very dissimilar. However, as the authors mentioned, this result may also indicate that the target must consist of pattern information in order to cause AB. In addition, Olson et al. found that the phonological length of the target affected the magnitude of $\mathrm{AB}$, but the visual length of the target did not affect the AB, even though it did affect target performance. Thus, it appears that short-term consolidation of the target, rather than its initial sensory registration, is of primary importance in determining the magnitude of the visual $\mathrm{AB}$. In fact, the effect of the +1 item is also seen to be a phenomenon caused by the target processing difficulty, because the +1 item can be processed together with the target and thus increases the target processing difficulty. Similarly, the global effect of all distractors can be explained by the influences of both target discriminability on the target processing difficulty and probe discriminability on the possibility of the probe being overwritten and decayed.

Whereas the visual $\mathrm{AB}$ has been the subject of quite extensive study, few studies have examined its auditory counterpart. Investigations of the auditory $\mathrm{AB}$ have used three types of materials - namely, spoken letters and digits (e.g., Arnell \& Jenkins, 2004; Arnell \& Jolicœur, 1999; Arnell \& Larson, 2002; Soto-Faraco \& Spence, 2002), spoken syllables (e.g., Duncan, Martens, \& Ward, 1997; Tremblay, Vachon, \& Jones, 2005), and tones (e.g., Mondor, 1998; Shen \& Mondor, 2006). Several of these studies have examined the effect of distractors on the auditory AB. In accordance with the evidence pertaining to the visual AB, Shen and Mondor found that deleting all distractors following the probe drastically reduced the magnitude of the auditory $\mathrm{AB}$, and several researchers have reported a global discrim- inability effect of all distractors in a sequence (e.g., Arnell \& Jolicœur, 1999; Shen \& Mondor, 2006; Tremblay et al., 2005). In contrast with studies of the visual $A B$, however, deleting the +1 item does not reduce the magnitude of the auditory AB (Mondor, 1998; Shen \& Mondor, 2006).

It appears to be clear that the +1 item is not processed together with the target and does not increase the target processing difficulty in auditory sequences. Moreover, although some researchers have reported the global discriminability effect, the effect may be due mainly to its influence on the overwriting and decay of the probe, but not on the target processing difficulty. Therefore, one important issue is whether there is a factor that can affect the target processing difficulty, thereby affecting the magnitude of the auditory AB.

Kahneman, Treisman, and Gibbs (1992) have argued that successive stimuli may be represented by the same object file, as long as they do not differ markedly. In contrast, successive stimuli that do differ substantially must be represented by separate object files. Kahneman et al. defined "an object file as a temporary episodic representation, within which successive states of an object are linked and integrated" (p. 175). Recently, Raymond (2003) suggested that the visual AB reflects a limitation in creating a new object file for the target, rather than a problem of incorporating a new feature into an existing object file. Raymond demonstrated that there was a significant visual AB when the target (arrowhead) was different from the distractors (tridents) at object level, but not when the target (trident with a thicker line) was different from the distractors at feature level, regardless of the probe's being different from the distractors at feature (trident with a short foot) or object (arrowhead) level. Furthermore, Raymond suggested that at the beginning of each RSVP sequence, an object file is created, and this file is continually updated as each similar object is presented. Presentation of a target that differs substantially from the preceding distractors requires the viewer to create a new object file, and this draws on capacitylimited attentional resources. If, while the target object file is being created, the probe is presented, its processing will be impaired because of a scarcity of resources, and an $\mathrm{AB}$ will result.

The present study was conducted to evaluate whether object file continuity may also have an influence on the auditory AB. There were two parts in each of the three experiment sets described below. Whereas in Part A of each experiment pure tones were used as distractors, in Part B, pulses were used as distractors. (In this context, a pulse is a sound that comprised a succession of six 5-msec pure-tone bursts, with each burst incorporating 1-msec onset and offset amplitude ramps. Thus, a pulse sound has a distinct, regular, amplitude modulation profile.) Pure tones and pulses based on the same carrier frequency differ in timbre (these sounds are described visually in Figure 1). In all experiments, the relationship between the target and the distractors was manipulated. The target and probe could differ from encompassing distractors either in frequency only (this is referred to as a one-attribute difference) or in both frequency and timbre (this is referred to as a two-attribute 


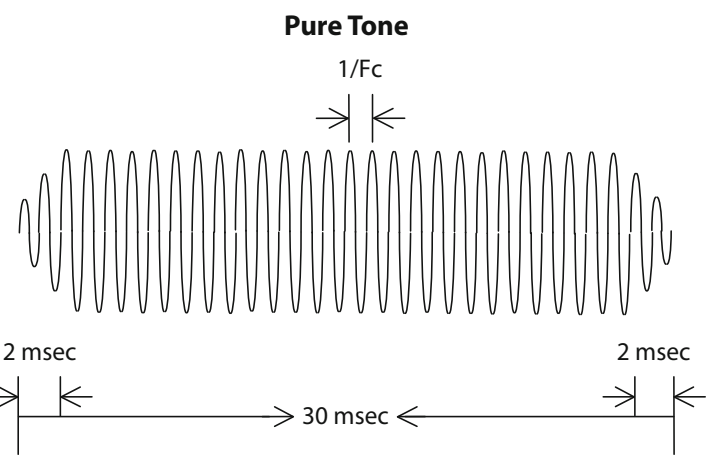

Six 5-msec Pulses

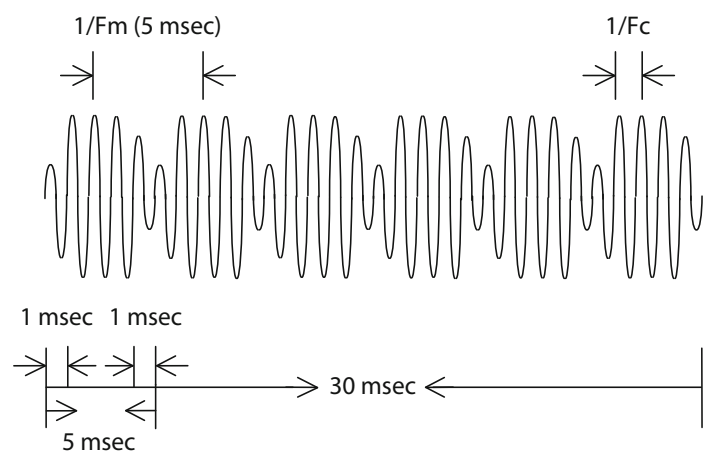

Figure 1. Top: A 30-msec pure tone is shown with only a carrier frequency $(\mathrm{Fc})$. It includes 2-msec linear onset/offset amplitude ramps. Bottom: Six 5-msec pulses with an Fc and a modulation frequency (Fm) are shown. There are 1-msec linear onset/offset amplitude ramps for each 5-msec pulse.

difference). Thus, for example, a 1500-Hz pure-tone target would differ in the two attributes from a stream of pulse distractors, each with a carrier frequency of $1000 \mathrm{~Hz}$.

According to Raymond's (2003) study, the visual AB reflects the requirement of generating an object file for the target. We reasoned that, in contrast with the oneattribute-difference condition, introducing two different attributes would increase the possibility of breaking auditory object file continuity and, as a result, more resources would be required for generating an object file for the target, and a larger auditory $\mathrm{AB}$ would be apparent. This was examined in all three sets of experiments. We conducted a brief experiment to determine whether changes in timbre and frequency would lead to the systematic changes in perceived difference on which our study was based. The results of this study confirmed that changes in frequency and timbre were additive, so that sounds that differed in one of these attributes were perceived as being less different than sounds that differed in both attributes (see the Appendix for complete proofs).

Shen and Mondor (2006) demonstrated that the overwriting of the probe by the distractors following it is a major factor in generating the auditory AB. Thus, the influence of the relationship between the probe and the distractors on the auditory AB was also examined in Experiments 2 and 3.

\section{EXPERIMENTS 1A AND 1B}

In Experiment 1, two types of sequences were employed: $2-1$ sequences, in which the target always differed from the distractors in two attributes (frequency, timbre), and the probe always differed from the distractors in one attribute (frequency); and 1-2 sequences, in which the target differed from the distractors in one attribute (frequency), and the probe differed from the distractors in two attributes (frequency, timbre). The target and the probe were always different from each other in one attribute (timbre). We reasoned that if a larger $\mathrm{AB}$ was apparent for $2-1$ sequences than for $1-2$ sequences, this would provide an initial indication that it may be affected by the requirement of generating an object file for the target.

We also compared probe detection performance when the target was to be attended with performance when the target was to be ignored, in order to address the possibility that low-level masking of the probe by the target may contribute to auditory $\mathrm{AB}$. If there is a larger $\mathrm{AB}$ in the targetattended condition than in the target-ignored condition, this will provide evidence that the auditory $\mathrm{AB}$ deficit is at least partially attentional in nature and does not simply reflect the effect of the sensory masking.

\section{Method}

Participants. One hundred sixty undergraduate students enrolled in an Introduction to Psychology course at the University of Manitoba participated in the experiment in exchange for course credit. They all had normal hearing, according to self-report.

Materials. The experiment was conducted using a Dell Pentium computer running E-Prime (Psychology Software Tools, Inc., 2001). Sounds were synthesized using Adobe Audition 1.5 at a sampling rate of $44100 \mathrm{~Hz}$. Sounds were presented at a comfortable intensity of about 70 dB SPL through Sony headphones (MDR-V600).

Each sequence consisted of 16 sounds. All sounds were $30 \mathrm{msec}$ in duration and included 2-msec linear onset/offset amplitude ramps in order to eliminate onset/offset clicks (shown in Figure 1). Several different sounds were synthesized in order to create a variety of different sequences, each defined by the acoustic nature of the distractor sounds and by the specific attributes of the target and probe that could be embedded within them. In Experiment 1A, the distractors were $1000-\mathrm{Hz}$ pure tones. For $2-1$ sequences, the target comprised six 5 -msec pulses with a carrier frequency of $1500 \mathrm{~Hz}$, and the probe was a $1500-\mathrm{Hz}$ pure tone. For $1-2$ sequences, the target was a $1500-\mathrm{Hz}$ pure tone, and the probe comprised six 5 -msec pulses with a carrier frequency of $1500 \mathrm{~Hz}$. In Experiment 1B, the distractors were six $5-\mathrm{msec}$ pulses with a carrier frequency of $1000 \mathrm{~Hz}$. For $2-1$ sequences, the target was a $1500-\mathrm{Hz}$ pure tone, and the probe comprised six 5-msec pulses with a carrier frequency of $1500 \mathrm{~Hz}$. For 1-2 sequences, the target comprised six 5-msec pulses with a carrier frequency of $1500 \mathrm{~Hz}$, and the probe was a $1500-\mathrm{Hz}$ pure tone. SOA between successive sounds was $95 \mathrm{msec}$, and the interstimulus interval (ISI) was $65 \mathrm{msec}$. The relative intensity of the left and right channels of each sound was varied: The possible intensity pairings of the right and left channels was always $70 \mathrm{~dB}$ SPL for one ear; for the other ear, the intensity changed randomly, ranging from 64 to $74 \mathrm{~dB}$ SPL (50\%-150\% amplification). These changes resulted in subjective location changes throughout each sequence (e.g., Bregman, 1993)

Procedure. On each trial, listeners were presented a sequence of 16 sounds, within which predefined target and probe sounds could be embedded. The target and the probe were each presented on $50 \%$ of the trials. This arrangement means that, with regard to target and probe occurrence, there were four types of trials, each of which oc- 
curred equally often (both target and probe presented, only target presented, only probe presented, neither target nor probe presented). The target could occur following either four or six distractor sounds, and the probe could occur in any of the first seven temporal positions following the target. The target position was randomized orthogonally with the probe position. On trials on which the target or probe was not presented, a distractor was presented in its place.

All participants responded to one or two questions that appeared on the computer screen following each trial. The first question always appeared immediately after the last sound in each sequence. When participants listened for both the target and the probe, the first question [Was the target present (press 1) or absent (press 0)?] appeared immediately after the end of each sequence, and the second question [Was the probe present (press 1) or absent (press 0)?] appeared immediately following an acceptable response to the first question. In contrast, when participants listened for only the probe, only the second question was presented.

For both Experiments 1A and 1B, there were four blocks of trials created by the combination of two tasks (listen for both target and probe, listen only for probe) with the target and probe pairing $(2-1,1-2)$. For each of these blocks, there were 32 practice trials and 224 experimental trials. Different groups of 20 participants were used for each. Random selection was used to determine the type of group to which each participant would be assigned. With regard to the practice trials, each participant was required to meet a criterion of $80 \%$ correct on both the target and probe judgments before beginning the experimental trials. No participant in the present study required more than two blocks of practice trials to reach this criterion.

Data analysis and design. For Experiments $1 \mathrm{~A}$ and $1 \mathrm{~B}$, we used a $2 \times 2 \times 2 \times 2 \times 7$ split-plot design with task (listen for both the target and the probe, listen only for the probe) and sequence type $(1-2,2-1)$ as between-participants factors and target presence (present, absent), probe presence (present, absent), and probe position $(+1$ to +7$)$ as within-participants factors.

All ANOVAs reported here used the Greenhouse-Geisser adjustment test because it is robust with respect to the sphericity assumption. A significant main effect of target presence and a significant interaction between target presence and probe position on probe processing accuracy indicated the occurrence of an $\mathrm{AB}$ (Seiffert \& Di Lollo, 1997). If the effects were significant, simple effects of target presence at each probe position were examined. All tests of simple effects were performed using Bonferroni's adjustment method, with $\alpha_{\mathrm{FW}}=.05$ (this is an appropriate method for controlling the $\alpha_{\mathrm{FW}}$ level; Maxwell \& Delaney, 2004).

\section{Results}

Target detection. Target detection accuracy for those trials on which the target was presented is described in Table 1 for all principal conditions in all of the present experiments.

In Experiment 1A, a $2 \times 2$ split-plot ANOVA with sequence type $(1-2,2-1)$ and probe presence (present, absent) was conducted, using the probability of accurate target detection as the dependent variable when the target was present. The analysis revealed a marginally significant main effect of sequence type $[F(1,38)=3.609, p=.065]$, indicating that the accuracy of target detection was slightly higher for 1-2 sequences than for 2-1 sequences. None of the other effects were significant (all other $p \mathrm{~s}>.15$ ).

In Experiment 1B, the two-way sequence type $\times$ probe presence split-plot ANOVA revealed a significant interaction between sequence type and probe presence $[F(1,38)=4.668, p<.05]$. This interaction arose because targets embedded in 2-1 sequences were more accurately detected than were targets embedded in 1-2 sequences
Table 1

Target Detection Accuracy (Mean and Standard Error), As a Function of Sequence Type, Stream, and Probe Presence, When the Target Was Present

\begin{tabular}{|c|c|c|c|c|}
\hline \multirow[b]{3}{*}{ Sequence Type } & \multicolumn{4}{|c|}{ Probe Presence } \\
\hline & \multicolumn{2}{|c|}{ Yes } & \multicolumn{2}{|c|}{ No } \\
\hline & $M$ & $S E$ & $M$ & $S E$ \\
\hline \multicolumn{5}{|c|}{ Experiment 1A } \\
\hline $1-2 \&$ full stream & .963 & .008 & .980 & .007 \\
\hline $2-1 \&$ full stream & .952 & .009 & .948 & .013 \\
\hline \multicolumn{5}{|c|}{ Experiment 1B } \\
\hline $1-2 \&$ full stream & .943 & .014 & .949 & .016 \\
\hline $2-1 \&$ full stream & .983 & .004 & .947 & .012 \\
\hline \multicolumn{5}{|c|}{ Experiment $2 \mathrm{~A}$} \\
\hline $1-1 \&$ full stream & .986 & .004 & .862 & .035 \\
\hline $2-2 \&$ full stream & .985 & .007 & .935 & .026 \\
\hline \multicolumn{5}{|c|}{ Experiment 2B } \\
\hline $1-1 \&$ full stream & .951 & .013 & .862 & .023 \\
\hline $2-2 \&$ full stream & .987 & .003 & .890 & .023 \\
\hline \multicolumn{5}{|c|}{ Experiment 3A } \\
\hline $1-1$ & & & & \\
\hline Full stream & .967 & .011 & .868 & .025 \\
\hline Silence preceding target & .934 & .011 & .928 & .013 \\
\hline Silence following probe & .942 & .017 & .929 & .017 \\
\hline $\begin{array}{l}\text { Silence preceding target } \\
\text { and following probe }\end{array}$ & .895 & .022 & .903 & .036 \\
\hline \multicolumn{5}{|l|}{$2-1$} \\
\hline Full stream & .959 & .011 & .965 & .010 \\
\hline Silence preceding target & .957 & .010 & .957 & .012 \\
\hline Silence following probe & .977 & .010 & .977 & .007 \\
\hline $\begin{array}{l}\text { Silence preceding target } \\
\text { and following probe }\end{array}$ & .969 & .009 & .960 & .010 \\
\hline \multicolumn{5}{|c|}{ Experiment 3B } \\
\hline $2-2$ & & & & \\
\hline Full stream & .996 & .002 & .902 & .022 \\
\hline Silence preceding target & .994 & .003 & .936 & .014 \\
\hline Silence following probe & 1.000 & 0 & .928 & .020 \\
\hline $\begin{array}{l}\text { Silence preceding target } \\
\text { and following probe }\end{array}$ & .993 & .003 & .983 & .006 \\
\hline $2-1$ & & & & \\
\hline Full stream & .977 & .007 & .968 & .006 \\
\hline Silence preceding target & .977 & .007 & .977 & .007 \\
\hline Silence following probe & .965 & .008 & .976 & .007 \\
\hline $\begin{array}{l}\text { Silence preceding target } \\
\text { and following probe }\end{array}$ & .970 & .008 & .976 & .007 \\
\hline
\end{tabular}

only when the probe was present. All other effects failed to reach significance (all other $p \mathrm{~s}>.10$ ).

Probe detection. Performance was examined separately for each principal condition using 2 (target presence) $\times 7$ (probe position) within-participants ANOVAs and using the conditional probability of accurate probe detection when the probe was present, given a correct target detection response, as the dependent variable. Performance in each condition is graphically described in Figure 2, and the results of those statistical analyses are summarized in Table 2.

In Experiment 1 $\mathrm{A}$, the results clearly demonstrate evidence of an $\mathrm{AB}$ in $2-1$ sequences for both the targetattended and the target-ignored conditions. There was also an $\mathrm{AB}$ in 1-2 sequences for the target-attended condition, but not for the target-ignored condition. The magnitude of the $\mathrm{AB}$ deficit was compared in the two types of $2-1$ 


\section{Pure-Tone Distractors}

A 1-2 With the Target Attended

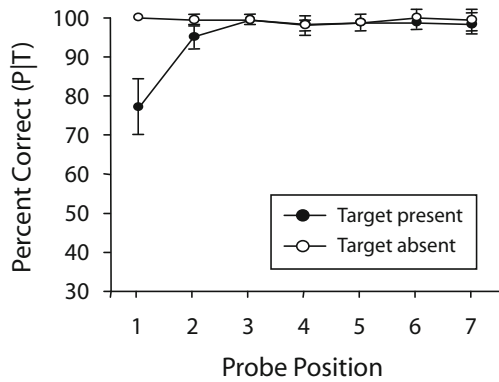

2-1 With the Target Attended

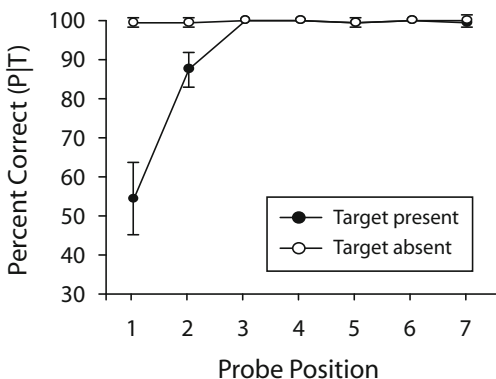

1-2 With the Target Ignored

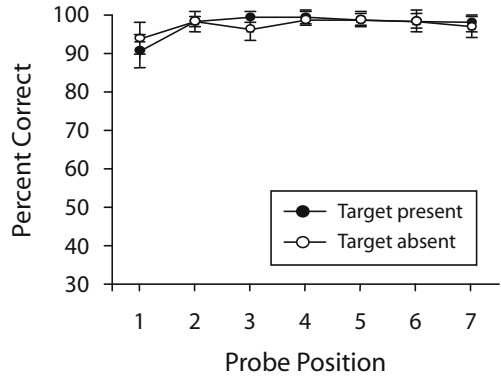

2-1 With the Target Ignored

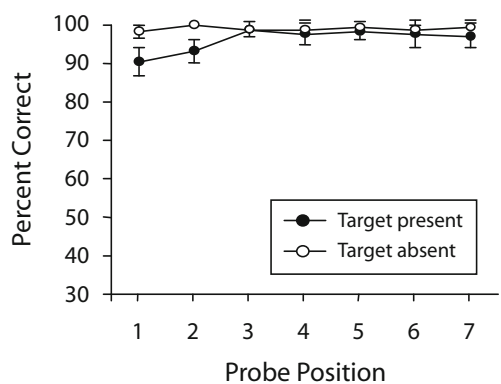

Pulse Distractors

B 1-2 With the Target Attended

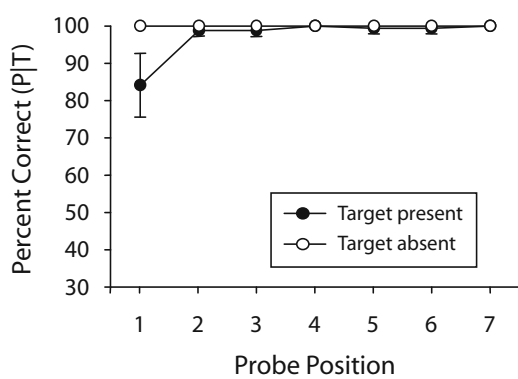

2-1 With the Target Attended

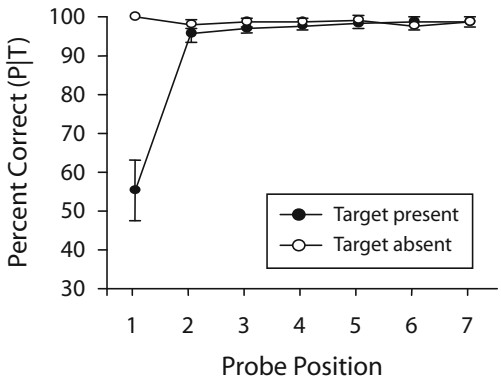

1-2 With the Target Ignored

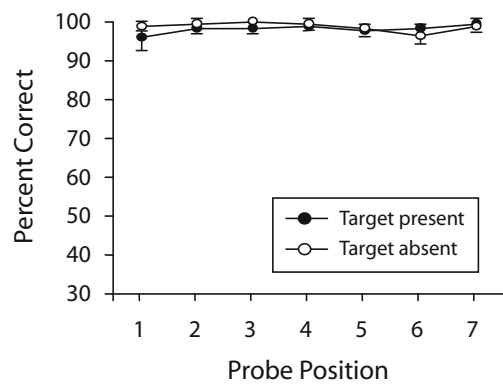

2-1 With the Target Ignored

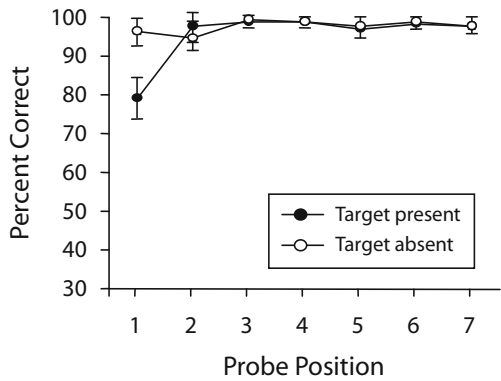

Figure 2. Probe detection accuracy in Experiment 1, as a function of the relationships between the target and the distractors and between the probe and the distractors (1-2 vs. 2-1), both when the target was to be attended and when it was to be ignored. Error bars represent 1 standard error. 
Table 2

$F$ Values of ANOVAs (Target Presence $\times$ Probe Position) for Each Principal Condition in Experiment 1, Including Main Effect of Target Presence, Main Effect of Probe Position, Interaction Between the Two, and Probe Deficits

\begin{tabular}{|c|c|c|c|c|}
\hline Sequence Type & $\begin{array}{c}\text { Target } \\
\text { Presence }\end{array}$ & $\begin{array}{l}\text { Probe } \\
\text { Position }\end{array}$ & Interaction & $\begin{array}{c}\text { Probe } \\
\text { Deficits }\end{array}$ \\
\hline \multicolumn{5}{|c|}{ Experiment $1 \mathrm{~A}$} \\
\hline $1-2$ & & & & \\
\hline Target-attended & $11.123^{* * * *}$ & $8.642^{* * *}$ & $9.549^{* * *}$ & +1 \\
\hline Target-ignored & 0.131 & $3.779^{* *}$ & 1.083 & No \\
\hline \multicolumn{5}{|l|}{$2-1$} \\
\hline Target-attended & $24.620^{* * * * *}$ & $27.866^{* * * * *}$ & $25.300^{* * * * *}$ & $+1,+2$ \\
\hline Target-ignored & $17.410^{* * *}$ & $3.097^{* *}$ & $3.197^{* *}$ & $+1,+2$ \\
\hline \multicolumn{5}{|c|}{ Experiment 1B } \\
\hline $1-2$ & & & & \\
\hline Target-attended & $7.827^{* *}$ & $5.289^{* *}$ & $5.289^{* *}$ & No \\
\hline Target-ignored & 1.212 & 1.723 & 1.377 & No \\
\hline \multicolumn{5}{|l|}{$2-1$} \\
\hline Target-attended & $46.786^{* * * * *}$ & $31.688^{* * * * *}$ & $34.681^{* * * * *}$ & +1 \\
\hline Target-ignored & $5.529^{* *}$ & $11.239^{* * * *}$ & $7.887^{* * *}$ & +1 \\
\hline
\end{tabular}

sequences in order to determine whether the requirement to attend to the target had any effect. A 2 (target task: unattended, attended) $\times 2$ (target presence: present, absent $) \times$ 7 (probe position: +1 to +7 ) split-plot ANOVA revealed a significant three-way interaction between target task, target presence, and probe position $[F(6,228)=14.364$, $p<.001]$. A 2 (target task) $\times 2$ (target presence) ANOVA at each probe position revealed a significant interaction at the +1 position $[F(1,38)=17.459, p<.001]$ (all other $p \mathrm{~s}>.10)$. Thus, the $\mathrm{AB}$ was larger when the target was attended than when the target was ignored.

The magnitudes of the $\mathrm{AB}$ apparent for the two types of sequences when the target was attended were directly compared using a 2 (sequence type) $\times 2$ (target presence) $\times$ 7 (probe position) split-plot ANOVA. A significant threeway interaction emerged from this analysis $[F(6,228)=$ $3.928, p<.05]$. A series of 2 (sequence type) $\times 2$ (target presence) split-plot ANOVAs performed for each probe position revealed a significant interaction at the +1 position $[F(1,38)=4.346, p<.05]$ and a marginally significant interaction at the +2 position $[F(1,38)=2.900$, $p=.097$ ] (all other $p \mathrm{~s}>.15$ ). Thus, when the target was attended, the $\mathrm{AB}$ deficit was larger for the $2-1$ sequences than for the 1-2 sequences.

In Experiment 1B, an $\mathrm{AB}$ was observed in 2-1 sequences for both the target-attended and target-ignored conditions. However, for the 1-2 sequences, there was a small $\mathrm{AB}$ when the target was presented and no $\mathrm{AB}$ at all when the target was ignored. The magnitudes of the $\mathrm{AB}$ deficit in the two types of 2-1 sequences were compared in order to determine whether the requirement to attend to the target had any effect. A 2 (target task: unattended, attended) $\times 2$ (target presence: present, absent $) \times 7$ (probe position: +1 to +7 ) split-plot ANOVA revealed a significant three-way interaction of target task, target presence, and probe position $[F(6,228)=7.582, p<.001]$. A 2 (target task) $\times 2$ (target presence) ANOVA at each probe position revealed a significant interaction at the +1 posi- tion $[F(1,38)=10.698, p<.01]$ and at the +2 position $[F(1,38)=6.013, p<.05]$ (all other $p \mathrm{~s}>.10$ ). Thus, for the 2-1 sequences, the $\mathrm{AB}$ was larger when the target was attended than when the target was ignored.

\section{Discussion}

Experiment 1 was conducted in order to examine whether object file continuity influences the auditory $\mathrm{AB}$. The results revealed a larger $\mathrm{AB}$ when the target was different from the distractors in both frequency and timbre than when the target was different from the distractors in frequency only. It appears that the requirement of generating an object file for the target may indeed play a role in determining the magnitude of the auditory AB. However, it is important to note that this is not the only possible interpretation. Especially, the larger $\mathrm{AB}$ that we observed for 2-1 sequences than for 1-2 sequences may have arisen either because of an increased processing demand associated with generating an object file for the target when it is markedly different from the distractors, or because the probe is more likely to be overwritten by the postprobe distractors when the probe differs from the distractors in a single attribute than when it differs from the distractors in two attributes. Shen and Mondor (2006) have shown that the overwriting of the probe by the distractors following it is a major factor in generating the auditory AB. In addition, whereas Experiment 1A showed a lower target detection accuracy associated with a larger $\mathrm{AB}$ in 2-1 sequences and a higher target detection accuracy associated with a smaller $\mathrm{AB}$ in 1-2 sequences, Experiment 1B revealed a higher target detection accuracy associated with a larger $\mathrm{AB}$ in the 2-1 sequences and a lower target detection accuracy associated with a smaller $\mathrm{AB}$ in the 1-2 sequences. It appears that the requirement of generating an object file for the target has an influence on auditory $\mathrm{AB}$ for pure-tone distractor sequences, but not for pulse distractor sequences. It may be that the overwriting of the probe is a more dominant factor for pulse distractor sequences. Experiment 2 was designed in part to address these competing accounts.

Although of secondary importance, the experiments were also conducted to examine whether low-level sensory masking of the probe by the target may cause the auditory AB. Two results are important in this regard. First, for 1-2 sequences, whereas an $\mathrm{AB}$ was apparent when the target was attended, no $\mathrm{AB}$ arose when the target was ignored. Second, for 2-1 sequences, the magnitude of the auditory $\mathrm{AB}$ was significantly larger when the target was attended than when the target was ignored. Were the $\mathrm{AB}$ caused only by sensory masking, its magnitude would not vary as a function of whether the target was attended. There are two possible explanations for the small $\mathrm{AB}$ deficit that was observed in 2-1 sequences when the target was ignored: sensory masking of the probe by the target or involuntary attentional capture of the target (e.g., Folk, Leber, \& Egeth, 2002; Jiang \& Chun, 2001; Shen \& Mondor, 2006). It is important to note that the target and the probe for 1-2 and 2-1 sequences in Experiment 1A were the same as those used for 2-1 and 1-2 sequences in Experiment 1B, respectively. If sensory masking of the probe by the target causes the auditory $\mathrm{AB}$, there should have been deficits for the 1-2 sequences in Experiment 1A and the 2-1 sequences in Ex- 
periment $1 \mathrm{~B}$, or for the 2-1 sequences in Experiment $1 \mathrm{~A}$ and the 1-2 sequences in Experiment 1B. However, there was a small $\mathrm{AB}$ in both experiments for the $2-1$ sequences and no $\mathrm{AB}$ at all for the 1-2 sequences. Thus, it does not appear that sensory masking played a role in generating the auditory $\mathrm{AB}$. The small AB for the $2-1$ sequences when the target was ignored could have been caused by involuntary attentional capture. This is consistent with previous reports that involuntary attentional capture is more likely to occur when a to-be-ignored item differs from distractors more saliently (e.g., Hillstrom \& Yantis, 1994).

Another issue related to the auditory AB is task switching. The possibility that the auditory $\mathrm{AB}$ may simply reflect the cost of switching from searching for a target to searching for a probe has been suggested (Chun \& Potter, 2001; Potter, Chun, Banks, \& Muckenhoupt, 1998). However, in Experiments $1 \mathrm{~A}$ and $1 \mathrm{~B}$, the target and the probe were always different from each other in one attribute (timbre), and both tasks were detection. In this situation, task switching is unlikely to happen (Visser, Bischof, \& Di Lollo, 1999). In addition, the fact that a larger $\mathrm{AB}$ was apparent for 2-1 sequences than for 1-2 sequences strongly suggests that a simple task-switching explanation is incorrect, because the target and the probe were exchanged in the two sequences. Some researchers (e.g., Allport, Styles, \& Hsieh, 1994; Yeung \& Monsell, 2003) have argued that unequal familiarity with two tasks (in our case, the target detection task and the probe detection task) could result in an asymmetric taskswitching effect. For example, Allport et al. reported that the task-switching deficit was larger when people switched from a less familiar to a more familiar task (i.e., color naming to word naming) than when people switched from a more familiar to a less familiar task (i.e., word naming to color naming). In the present experiments, the target and the probe for the 2-1 and 1-2 sequences in Experiment 1A were exchanged with those for the 1-2 and 2-1 sequences in Experiment 1B, respectively. If unequal familiarity with the target and probe detection was responsible for the different magnitudes of the auditory $\mathrm{AB}$, then, for example, a larger $\mathrm{AB}$ should have been apparent either for the 2-1 sequences in Experiment $1 \mathrm{~A}$ and the 1-2 sequences in Experiment $1 \mathrm{~B}$, or for the 1-2 sequences in Experiment $1 \mathrm{~A}$ and the 2-1 sequences in Experiment 1B. This was not the case. The results showed that there was a larger $\mathrm{AB}$ for the 2-1 sequences than for the 1-2 sequences in both Experiments $1 \mathrm{~A}$ and 1B. Moreover, Allport and Hsieh (2001) have argued that a task-switching deficit $(800-900 \mathrm{msec})$ is normally longer lasting than an AB deficit (400-500 msec), and, given that the deficit we observed here is quite brief, this is inconsistent with a simple task-switching account. In addition, the materials used in the present study were derived from those of Shen and Mondor (2006). However, in that study, the target could be one of the 21 different carrier frequency pulses, and the distractors could be one of the 21 different frequency pure tones as well. That arrangement resulted in longer ABs (400-500 msec). Accordingly, the shorter $A B$ in the present study could have occurred because there was only one possibility for the target in one type of sequence and the distractors were homogenous (this arrangement was used for manipulating the relationship be- tween the target and distractors). This arrangement could result in shorter consolidation duration for the target and could have caused shorter AB.

\section{EXPERIMENTS 2A AND 2B}

In Experiment 1, when the target differed from the distractors by two attributes, the probe always differed from the distractors by one attribute. In contrast, when the target differed from the distractors by a single attribute, the probe always differed from distractors by two attributes. This design permits the logical possibility that the robust $\mathrm{AB}$ that we observed for the 2-1 sequences may actually have been caused by the similarity of the probe to the distractors and not by any requirement of generating an object file for the target, although Raymond's (2003) study showed that the magnitude of the visual $\mathrm{AB}$ is not related to the relationship of the probe to the distractors. Arnell and Jenkins (2004) have argued that probe-distractor similarity is a very important determinant of both visual and auditory AB. Shen and Mondor (2006) provided evidence that the overwriting of the probe by the distractors following it is a major factor in generating the auditory AB. Thus, it is possible that more overwriting of the probe by the distractors following it occurs when the probe differs from the distractors in a single attribute than when it differs from the distractors in two attributes. The present experiment was conducted in order to examine this possibility.

Two types of sequences were used. For one type of sequence (2-2 sequences), the target and the probe differed from the distractors in two attributes (frequency, timbre). For the other type of sequence (1-1 sequences), the target and the probe differed from the distractors in a single attribute (frequency). For both types of sequences, the target and probe differed from each other in one attribute (frequency). If a requirement to create an object file for the target is critical in generating the $\mathrm{AB}$, performance for the 2-2 sequences should be quite similar to that obtained for the 2-1 sequences in Experiment 1. In contrast, if the overwriting of the probe is the principal cause of the auditory $\mathrm{AB}$, performance for the 1-1 sequences should be similar to that apparent for the 2-1 sequences in Experiment 1.

The accuracy of the probe detection was examined both when the target was to be attended and when it was to be ignored, in order to evaluate, once again, the contribution of sensory masking.

\section{Method}

Participants. Eighty undergraduate students enrolled in an Introduction to Psychology course at the University of Manitoba participated in the experiment in exchange for course credit. They all had normal hearing, according to self-report.

Materials. The computer, sound system, and sounds were the same as those used in Experiments 1A and 1B. In Experiment 2A, distractors were $1000-\mathrm{Hz}$ pure tones. For the 1-1 sequences, the target was either a 1250 - or a $1500-\mathrm{Hz}$ pure tone, and the probe was either a $1500-$ or a $1250-\mathrm{Hz}$ pure tone. For the $2-2$ sequences, the target consisted of pulse sounds comprising six 5-msec units, each with a carrier frequency of 1250 or $1500 \mathrm{~Hz}$, and the probe consisted of pulse sounds comprising six 5-msec units, each with a carrier frequency of 1500 or $1250 \mathrm{~Hz}$. In Experiment 2B, the distractors were pulse sounds comprising six 5-msec units, each with a carrier frequency of 
$1000 \mathrm{~Hz}$. For the 1-1 sequences, the target consisted of pulse sounds comprising six 5-msec units, each with a carrier frequency of 1250 or $1500 \mathrm{~Hz}$, and the probe consisted of pulse sounds comprising six 5 -msec units, each with a carrier frequency of 1500 or $1250 \mathrm{~Hz}$. For the $2-2$ sequences, the target was either a $1250-$ or a $1500-\mathrm{Hz}$ pure tone, and the probe was either a $1500-$ or a $1250-\mathrm{Hz}$ pure tone. Note that the target and the probe were always different in all of these types of sequences. For each type of sequence, the particular target and probe sounds used were counterbalanced across participants.

Procedure. The procedure used was, in all important facets, the same as that used in Experiment 1. However, performance was examined for two new types of sequences-namely, 1-1 sequences, for which the target and probe differed from the distractors in one attribute (frequency), and 2-2 sequences, for which the target and probe differed from the distractors in two attributes (frequency, timbre). Also in contrast with the procedure used in Experiment 1, all of the participants were presented both types of sequences.

For both experiments, there were four blocks of trials created by the combination of tasks (listen for both target and probe, listen only for probe) and sequence types (1-1,2-2). Each participant completed both the 2-2 and the 1-1 trial blocks for either the target-attended condition or the target-ignored condition. Different groups of 20 participants were used for each condition. The order in which these trial blocks were completed was counterbalanced across participants. Random selection was used to determine which participants were tested in the target-attended or the target-ignored conditions. In addition, half of the participants were examined in the $1250-\mathrm{Hz}$ target$1500-\mathrm{Hz}$ probe condition, and the other half of the participants were examined in the $1500-\mathrm{Hz}$ target $-1250-\mathrm{Hz}$ probe condition. All other procedural details were the same as for Experiments 1A and 1B.

Data analysis and design. For Experiments $2 \mathrm{~A}$ and $2 \mathrm{~B}$, we used a $2 \times 2 \times 2 \times 2 \times 7$ split-plot design with task (listen for both target and probe, listen only for probe) as the between-participants factor and sequence type (1-1,2-2), target presence (present, absent), probe presence (present, absent), and probe position $(+1$ to +7$)$ as withinparticipants factors. The methods of analysis were the same as those in Experiments 1A and 1B.

\section{Results}

Target detection. In Experiment 2A, a 2 (sequence type: $2-2,1-1) \times 2$ (probe presence: present, absent) within-participants ANOVA was conducted, using the probability of accurate target detection as the dependent variable when the target was present. The analysis revealed a significant main effect of probe presence $[F(1,19)=$ $28.725, p<.001]$. The accuracy of target detection was higher in the probe-present sequences than in the probeabsent sequences. Neither the main effect of sequence type $[F(1,19)=1.268, p=.274]$ nor the interaction between the two $[F(1,19)=1.330, p=.263]$ was significant.

In Experiment 2B, the two-way (sequence type $\times$ probe presence) within-participants ANOVA revealed a significant main effect of probe presence $[F(1,19)=33.616, p<.001]$. The accuracy of target detection was higher in the probepresent sequences than in the probe-absent sequences. The main effect of sequence type was marginally significant $[F(1,19)=2.920, p=.104]$. The accuracy of target detection was slightly higher in the 2-2 sequences than in the 1-1 sequences. The interaction between sequence type and probe presence was not significant $(F<1)$.

Probe detection. Performance was examined separately for each principal condition using 2 (target presence) $\times 7$ (probe position) within-participants ANOVAs and using the conditional probability of accurate probe detection when the
Table 3

$F$ Values of ANOVAs (Target Presence $\times$ Probe Position) for Each Principal Condition in Experiment 2, Including Main Effect of Target Presence, Main Effect of Probe Position, Interaction Between the Two, and Probe Deficits

\begin{tabular}{ccccc}
\hline & Target & Probe & & Probe \\
Sequence Type & Presence & Position & Interaction & Deficits \\
\hline
\end{tabular}

Experiment 2A

$1-1$

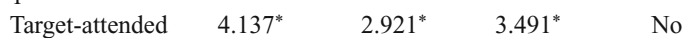

$\begin{array}{llll}\text { Target-ignored } & 32.263^{* * * *} & 1.413 & 0.613\end{array}$

$2-2$

Target-attended $\quad 9.380^{* * *} \quad 6.100^{* * *} \quad 6.749^{* * *} \quad+1.144 \quad+$

$\begin{array}{llll}\text { Target-ignored } & 10.505^{* * *} & 1.144 & 0.419\end{array}$

Experiment 2B

$1-1$

Target-attended $\quad 5.770^{* * *} \quad 13.679^{* * *} \quad 7.927^{* * *} \quad+1$

$\begin{array}{llll}\text { Target-ignored } & 5.668^{* *} & 6.343^{* * * *} & 2.932^{* *}\end{array}$

$2-2$

$\begin{array}{llll}\text { Target-attended } & 1.574 & 0.569 & 1.797\end{array}$

\begin{tabular}{|c|c|c|c|}
\hline Target-ignored & $10.764^{* * *}$ & 1.077 & 0.588 \\
\hline
\end{tabular}

${ }^{*} p<.10 .{ }^{* *} p<.05 .{ }^{* * *} p<.01 .{ }^{* * * *} p<.001$.

probe was present, given a correct target detection response, as the dependent variable. Performance in each condition is graphically described in Figure 3, and the results of those statistical analyses are summarized in Table 3.

In Experiment $2 \mathrm{~A}$, the results revealed a significant $\mathrm{AB}$ in the 2-2 sequences and a marginally significant $A B$ in the 1-1 sequence when the target was attended, but no $\mathrm{AB}$ when the target was ignored. The magnitudes of the $\mathrm{AB}$ deficits in the 1-1 and 2-2 sequences, which were apparent when the target was attended, were compared using a 2 (sequence type: $1-1,2-2) \times 2$ (target presence: present, absent $) \times 7$ (probe position: +1 to +7 ) within-participants ANOVA. Although this analysis revealed an insignificant three-way interaction $[F(1,19)=1.221, p=.307]$, a marginally significant two-way interaction between sequence type and target presence was apparent $[F(1,19)=3.615, p=.073]$. The results of a series of 2 (sequence type) $\times 2$ (target presence) ANOVAs performed for each probe position revealed only a marginally significant interaction at the +3 position $[F(1,38)=4.031, p=.059]($ all other $p \mathrm{~s}>.10)$.

In Experiment 2B, the results revealed a significant $A B$ in the 1-1 sequences when the target was attended, but there was no $\mathrm{AB}$ in the other three conditions. Note that although there were significant main effects and interaction in the 1-1 sequences when the target was ignored, the probe detection accuracy was higher when the target was present than when the target was absent. Thus, there was no $\mathrm{AB}$ in this condition either.

\section{Discussion}

Experiments $2 \mathrm{~A}$ and $2 \mathrm{~B}$ were performed primarily in order to evaluate the possibility that the larger $\mathrm{AB}$ apparent in Experiment 1 for the 2-1 sequences than for the 1-2 sequences arose because of differences between the two sequences in the probability of the probe being overwritten by the postprobe distractors. Were this the case in the present experiment, there should have been a larger $\mathrm{AB}$ for the 1-1 sequences than for the 2-2 sequences. However, the 


\section{Pure-Tone Distractors}

A 1-1 With the Target Attended

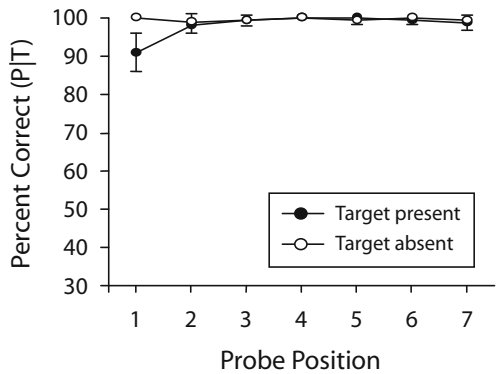

2-2 With the Target Attended

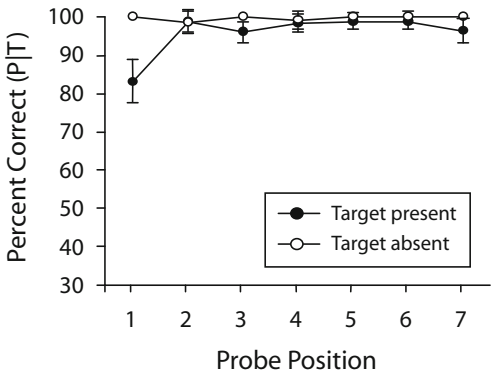

1-1 With the Target Ignored

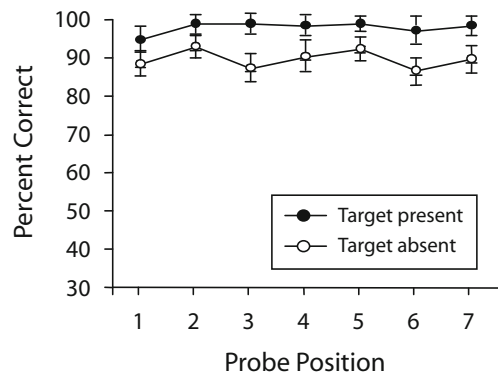

2-2 With the Target Ignored

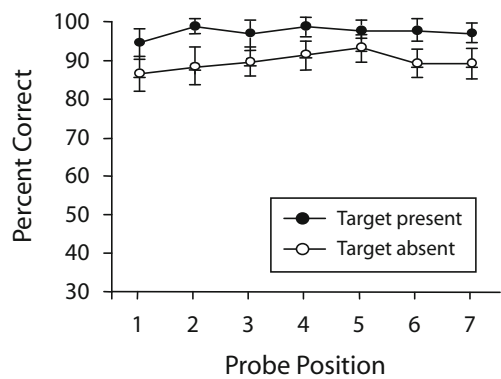

Pulse Distractors

B 1-1 With the Target Attended
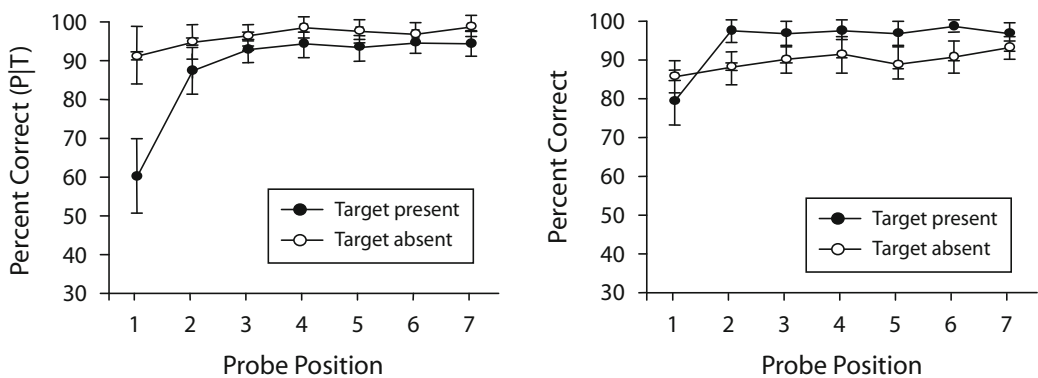

2-2 With the Target Attended

2-2 With the Target Ignored
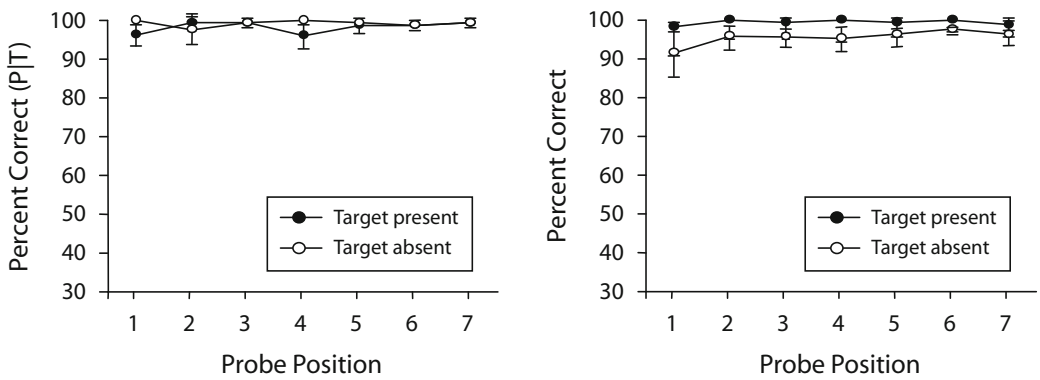

Figure 3. Probe detection accuracy in Experiment 2, as a function of the relationships between the target and the distractors and between the probe and the distractors (1-1 vs. 2-2), both when the target was to be attended and when it was to be ignored. Error bars represent 1 standard error. 
results of Experiment $2 \mathrm{~A}$ showed that small $\mathrm{AB}$ deficits were apparent for both types of sequences. It is probably because the target detection accuracy in both conditions was very good (they were higher than $98 \%$ when both the target and the probe were presented; see Table 1) - namely, the target processing difficulty was very low, and the requirement on the resources to generate and consolidate a new object file for the target would be very small. Thus, the delay of the probe processing would be too short, and the probability of the overwriting of the probe by the distractors following it would be very low, and this resulted in small $\mathrm{AB}$ deficits for both conditions.

The results of Experiment $2 \mathrm{~B}$ showed that there was a significant $\mathrm{AB}$ for the $1-1$ sequences, but that there was no $\mathrm{AB}$ for the 2-2 sequences. Although somewhat surprising, this may reveal an important factor governing the expression of the auditory AB. Recall that the distractors in this experiment were six 5-msec pulses with a carrier frequency of $1000 \mathrm{~Hz}$ (see Figure 1). Each pulse is based on a $1000-\mathrm{Hz}$ pure tone. Each individual pulse was $5 \mathrm{msec}$ in duration, and the successive presentation of six of these may be said to create a sound with a modulation frequency of $200 \mathrm{~Hz}$. Many studies have addressed the perception of modulated sounds (e.g., Moore, 2003; Moore \& Jorasz, 1992, 1996; Yost, 2000; Yost \& Sheft, 1989; Yost, Sheft, \& Opie, 1989). These studies have shown that perception of a modulated sound will be impaired when it is presented in the context of similarly modulated distractor sounds; this is called comodulation. This appears to occur because a primitive perceptual grouping mechanism considers sounds with the same modulation frequency to have arisen from the same sound source. Critically, such grouping may occur even when carrier frequency varies across sounds. When such grouping occurs, distinguishing one modulated sound from another is difficult and requires the use of central capacity-limited processing resources (see, e.g., Moore \& Jorasz, 1996).

With regard to the results of Experiment 2B in the present study, it is possible that for the 1-1 sequences, the target and the probe were grouped with the distractors, as a consequence of their comodulation, and this may have increased the demand for the central capacity-limited resources needed for processing the target, and thereby extended the delay in processing the probe. Of course, according to the two-stage model, an increased delay in processing the probe should provide an increased opportunity for the overwriting or decay of its representation. Furthermore, this effect may also apply to probe perception, in that a probe with the same modulation frequency may be more easily integrated into a stream with the distractors, and therefore be more easily overwritten. Thus, it may be for these reasons that a relatively large $\mathrm{AB}$ arose for the 1-1 sequences in Experiment 2B. For the 2-2 sequences in Experiment 2B, the distractors were pulses, and the target was a pure tone. The object file created at the beginning of the sequence for the pulse distractors would include information about both modulation frequency and carrier frequency, and processing the target with only carrier frequency may have required a minimal degree of the central capacity-limited resources because the object file for the target could have been derived from the initial file for the pulse distractor. In this circumstance, the duration of the probe-processing delay would be very short, and the opportunity for the probe to be overwritten and passively decay would be small. Furthermore, the likelihood of the pure-tone probe's being overwritten by the pulse distractors following it would also be small, because of the distractors' dissimilarity. Together, these effects would indicate that perception of the probe would not likely be impaired. This explanation is consistent with the fact that the target detection accuracy for the 2-2 sequences was higher than that for the 1-1 sequences; the target processing difficulty was lower for the former than for the latter.

Note that in Experiment 1B, the distractors were also pulses. However, a larger AB was apparent for the $2-1$ sequences than for the 1-2 sequences. For the 2-1 sequences, an object file for the pure-tone target could have been derived from the initial file for the pulse distractors, and this would require relatively few processing resources. Thus, the duration of the probe-processing delay would be brief, and the opportunity for the overwriting and passive decay of the probe would be correspondingly reduced. Notwithstanding this brief probe-processing delay, however, there was quite a high possibility of the pulse probe's being overwritten by the postprobe pulse distractors, owing to their similarity; the probe and the distractors were comodulated. Consequently, a large AB would be produced. For the 1-2 sequences, although the target and distractors were only different in carrier frequency, a significant amount of resources was still required for processing it because of the high similarity of the target and the distractors, due to their common modulation profile (see, e.g., Moore \& Jorasz, 1996). Thus, the duration of the probe-processing delay would be relatively long, and the opportunity for the overwriting and decay of the probe would be relatively high. However, in spite of the lengthy delay in processing the probe, there would be a low possibility of the probe's being overwritten by the postprobe distractors, because of their low similarity. Thus, for the 1-2 sequences, although the delay in processing the probe was relatively long, the dissimilarity of the probe and the distractors meant that there was little overwriting of the probe representation, so only a small AB was apparent for these sequences. This explanation is also consistent with the fact that target detection accuracy was lower in the 1-2 sequences than in the 2-1 sequences when the target and the probe were both present.

Experiments 2A and 2B were also conducted in order to assess the effect of sensory masking. The results showed that there were no $\mathrm{AB}$ deficits in either of the two targetignored conditions. Thus, the auditory $\mathrm{AB}$ does not appear to reflect the effect of sensory masking, because such masking should be unaffected by whether the target was to be attended. Note that the accuracy of probe detection was lower in target-absent sequences than it was in target-present sequences. This effect may have occurred because of the similarity of the target to the probe and because of low-level processing of the target when it was to be ignored. When the probe was present alone, it was difficult for participants to judge whether it was the target or the probe. In contrast, when both the target and the probe were present, no such determination was required. These results, then, provide 
further evidence that task switching does not contribute in any meaningful way to performance, because the target and the probe were so similar in these two experiments.

Taken together, the results of Experiments $1 \mathrm{~A}$ and $1 \mathrm{~B}$ and of Experiments $2 \mathrm{~A}$ and $2 \mathrm{~B}$ clearly show that neither the requirement of creating an object file for the target nor the overwriting of the probe by the distractors following it, on their own, can provide complete explanations of the auditory $\mathrm{AB}$, but both of these factors contribute to the generation of the auditory AB. Of course, under different conditions, one factor might be more dominant than another. It appears that for pulse distractor sequences, the overwriting of the probe is a more dominant factor than the requirement of creating and consolidating an object for the target, but the requirement of creating and consolidating an object file for the target is more important for pure-tone distractor sequences than for pulse distractor sequences.

\section{EXPERIMENTS 3A AND 3B}

The results of Experiments $1 \mathrm{~A}$ and $1 \mathrm{~B}$ and of Experiments $2 \mathrm{~A}$ and $2 \mathrm{~B}$ may be interpreted in light of the effects of the requirement to generate and consolidate an object file for the target, with the likelihood of the probe representation either decaying or being overwritten while awaiting processing. Experiments $3 \mathrm{~A}$ and $3 \mathrm{~B}$ were designed to provide some converging evidence of the role of these factors in generating the auditory $\mathrm{AB}$.

If it is the case that the requirement to create an object file for the target plays an important role in generating the $\mathrm{AB}$, it follows that an $\mathrm{AB}$ is more likely to be observed if the target happens to be the first item in a sequence, because a new object file must be created for the target regardless of its relationship to the subsequent distractors under this condition. Experiments $3 \mathrm{~A}$ and $3 \mathrm{~B}$ were designed both to examine this issue and to provide an opportunity to replicate the result reported by Shen and Mondor (2006), that only a very small AB remains when all of the distractors following the probe are replaced by silence.

The choice of sequences to use in Experiments $3 \mathrm{~A}$ and $3 \mathrm{~B}$ was driven by the results of the previous experiments. As in those experiments, distractors were pure tones in Experiment 3A and pulses in Experiment 3B. In Experiment $3 \mathrm{~A}$, performance was examined both for the 2-1 sequences, for which a large $\mathrm{AB}$ was apparent in Experiment $1 \mathrm{~A}$, and for the 1-1 sequences, for which little $\mathrm{AB}$ had been apparent in Experiment 2A. In Experiment 3B, performance was examined for the 2-1 sequences, for which a large $\mathrm{AB}$ was apparent in Experiment $1 \mathrm{~B}$, and for the 2-2 sequences, for which no $\mathrm{AB}$ was apparent in Experiment 2B. We examined performance for 2-1 sequences because these had shown a large $A B$; therefore, any reduction in the $\mathrm{AB}$ associated with the elimination of distractors - particularly those following the probewould be easily observed. Similarly, we examined performance for the 1-1 and 2-2 sequences, because no or little $\mathrm{AB}$ deficit had been apparent for these, so any increase in the magnitude of the AB deficit associated with eliminating distractors - particularly those preceding the targetwould be easily observed.

\section{Method}

Participants. Eighty undergraduate students enrolled in an Introduction to Psychology course at the University of Manitoba participated in the experiment in exchange for course credit. They all had normal hearing, according to self-report.

Materials. The computer, sound system, and sound characteristics were all the same as those in the previous experiments. In Experiment $3 \mathrm{~A}$, for both the $1-1$ and $2-1$ sequences, the distractors were $1000-\mathrm{Hz}$ pure tones and the probe was a $1500-\mathrm{Hz}$ pure tone. However, for the $1-1$ sequences the target was a $1250-\mathrm{Hz}$ pure tone; for the $2-1$ sequences, it was pulse sounds comprising six 5 -msec units, each with a carrier frequency of $1500 \mathrm{~Hz}$. In Experiment 3B, for the 2-2 and 2-1 sequences, the distractors were pulse sounds comprising six 5-msec units, each with a carrier frequency of $1000 \mathrm{~Hz}$, and the target was a $1500-\mathrm{Hz}$ pure tone. However, for the $2-2$ sequences, the probe was a $1250-\mathrm{Hz}$ pure tone; for the $2-1$ sequences, it consisted of pulse sounds comprising six 5-msec pulses with a carrier frequency of $1500 \mathrm{~Hz}$.

Procedure. For each sequence type, the presence and placement of distractors were manipulated across four conditions. Whereas in the full-stream condition, a full stream of distractors was presented, distractors were selectively deleted in the three other conditions. In one of these, all distractors preceding the target were replaced with silence. In a second condition, all distractors following the probe were replaced with silence. In a final condition, all distractors that both preceded the target and followed the probe were replaced with silence. Participants were required to make detection judgments for both the target and the probe. For each of these conditions, there were 32 practice trials and 224 experimental trials. Each participant completed all four conditions for one type of sequence: 2-1 or 1-1 in Experiment 3A, or 2-1 or 2-2 in Experiment 3B. A Latin square was used to balance the order in which the four conditions were completed across participants. Random selection was used to determine the type of sequence that each participant would be presented. Each participant was required to meet a criterion of $80 \%$ correct on both target and probe judgments on the practice trials before beginning the experimental trials.

Data analysis and design. For both Experiments $3 \mathrm{~A}$ and $3 \mathrm{~B}$, a $2 \times 4 \times 2 \times 2 \times 7$ split-plot design with sequence type (2-1, 1-1, for Experiment 3A; 2-1, 2-2 for Experiment 3B) as a betweenparticipants factor and stream (full, silence preceding the target, silence following the probe, silence preceding the target and following the probe), target presence (present, absent), probe presence (present, absent), probe presence (present, absent), and probe position $(+1$ to $+7)$ as within-participants factors. The methods of analysis were the same as those used in the previous experiments.

\section{Results}

Target detection. In Experiment $3 \mathrm{~A}$, we used a $2 \times$ $4 \times 2$ split-plot ANOVA with sequence type $(2-1,1-1)$ as a between-participants factor and stream (full, silence preceding the target, silence following the probe, silence preceding the target and following the probe) and probe presence (present, absent) as within-participants factors, using the probability of accurate target detection as the dependent variable when the target was present. The analysis revealed significant three-way interaction between target, stream, and probe presence $[F(3,114)=7.830, p<.001]$. This three-way interaction was decomposed by examining performance for the 1-1 and 2-1 sequences separately. For the 2-1 sequences, there was no significant main effect of stream $[F(3,57)=1.548, p=.223]$ or of probe presence $(F<1)$, nor was there an interaction between the two $(F<1)$. In contrast, for the $1-1$ sequences, although the main effect of stream was not significant $[F(3,57)=$ $1.829, p=.176]$, both the main effect of probe presence $[F(1,19)=4.916, p<.05]$ and the interaction between the two factors $[F(3,57)=8.395, p<.001]$ were significant. 
The two-way interaction was decomposed by examining performance for the probe-present and probe-absent conditions separately. When the probe was absent, the simple effect of stream was not significant $(F<1)$. However, when the probe was present, the simple effect of stream was significant $[F(3,57)=5.111, p<.05]$. Furthermore, multiple comparisons using Bonferroni's adjustment revealed significantly worse target detection, relative to the full-stream condition, when no distractors preceded the target and when silence preceded the target and followed the probe, but not when silence followed the probe.

In Experiment 3B, we conducted a $2 \times 4 \times 2$ splitplot ANOVA with sequence type $(2-2,2-1)$ as a betweenparticipants factor and stream (full, silence preceding the target, silence following the probe, silence preceding the target and following the probe), probe presence (present, absent) as within-participants factors using the probability of accurate target detection as the dependent variable when the target was present. The analysis revealed significant three-way interaction between sequence type, stream, and probe presence $[F(3,114)=4.305, p<.01]$. Furthermore, for the $2-1$ sequences, the main effects of stream, probe position, and their interaction were not significant (all $p s>.15$ ). In contrast, for the $2-2$ sequences, the main effects of stream $[F(3,57)=6.266, p<.01]$ and probe presence $[F(1,19)=21.668, p<.001]$ were significant, as was their interaction $[F(3,57)=8.842, p<.001]$. When the probe was absent, the simple effect of stream was significant $[F(3,57)=7.701, p<.01]$, indicating that deleting distractors from part of a sequence increased the accuracy of target detection. Furthermore, multiple comparisons with Bonferroni's adjustment were conducted in order to compare each of the other three conditions to the full-stream conditions, and results revealed significantly better target detection when silence both preceded the target and followed the probe, but not when silence only preceded the target or followed the probe. However, when the probe was present, the simple effect of stream was not significant $[F(3,57)=1.786, p=.179]$.

Probe detection. Performance was examined separately for each principal condition using 2 (target presence) $\times 7$ (probe position) within-participants ANOVAs; the conditional probability of accurate probe detection when the probe was present, given a correct target detection response, served as the dependent variable. Performance in each condition is graphically described in Figure 4, and the results of those statistical analyses are summarized in Table 4.

Examination of performance for each sequence type when a full set of distractors was presented reveals a nice replication of the results of the previous experiments. Thus, for sequences within which pure tones were used as distractors, whereas a marginally significant $\mathrm{AB}$ was apparent for the 1-1 sequences (as in Experiment 2A), a robust $\mathrm{AB}$ was apparent for the 2-1 sequences (as in Experiment 1A). Similarly, for sequences within which pulses were used as distractors, whereas a strong $\mathrm{AB}$ was apparent for the 2-1 sequences (as in Experiment 1B), no evidence of an auditory $\mathrm{AB}$ was apparent for the 2-2 sequences (as in Experiment 2B).

Most critical, however, are the effects of deleting the distractors preceding the target on performance, and these are discussed below.

In Experiment $3 \mathrm{~A}$, for the 1-1 sequences, the results revealed an $\mathrm{AB}$ for full-stream distractor sequences and

Table 4

$F$ Values of ANOVAs (Target Presence $\times$ Probe Position) for Each Principal Condition in Experiment 3, Including Main Effect of Target Presence, Main Effect of Probe Position, Interaction Between the Two, and Probe Deficits

\begin{tabular}{|c|c|c|c|c|}
\hline Sequence Type & $\begin{array}{c}\text { Target } \\
\text { Presence }\end{array}$ & $\begin{array}{l}\text { Probe } \\
\text { Position }\end{array}$ & Interaction & $\begin{array}{c}\text { Probe } \\
\text { Deficits }\end{array}$ \\
\hline \multicolumn{5}{|c|}{ Experiment $3 \mathrm{~A}$} \\
\hline \multicolumn{5}{|l|}{$1-1$} \\
\hline Full Stream & $3.922^{*}$ & $3.092^{* *}$ & $3.051^{* *}$ & No \\
\hline Silence preceding target & $23.972^{* * * *}$ & $17.650^{* * * *}$ & $18.456^{* * * *}$ & +1 \\
\hline Silence following probe & 1.104 & 0.663 & 1.063 & No \\
\hline Silence preceding target and following probe & $7.597^{* *}$ & 0.718 & 2.002 & No \\
\hline \multicolumn{5}{|l|}{$2-1$} \\
\hline Full Stream & $25.491^{* * * *}$ & $13.137^{* * * * *}$ & $13.293^{* * * * *}$ & $+1,+2,+3$ \\
\hline Silence preceding target & $25.419^{* * * * *}$ & $36.771^{\text {***** }}$ & $33.408^{* * * * *}$ & +1 \\
\hline Silence following probe & $7.392^{* *}$ & $3.016^{*}$ & $2.728^{*}$ & No \\
\hline Silence preceding target and following probe & $8.220^{* *}$ & $4.148^{* *}$ & $2.912^{*}$ & No \\
\hline \multicolumn{5}{|c|}{ Experiment 3B } \\
\hline \multicolumn{5}{|l|}{$2-1$} \\
\hline Full Stream & $25.073^{* * * *}$ & $17.260^{* * * * *}$ & $17.949^{* * * *}$ & +1 \\
\hline Silence preceding target & $40.861^{* * * *}$ & $30.828^{* * * *}$ & $33.771^{* * * * *}$ & +1 \\
\hline Silence following probe & $9.196^{* * *}$ & 1.545 & 1.353 & No \\
\hline Silence preceding target and following probe & $19.238^{* * * *}$ & $3.979^{* *}$ & 2.220 & +1 \\
\hline \multicolumn{5}{|l|}{$2-2$} \\
\hline Full Stream & 0.763 & 1.534 & 0.375 & No \\
\hline Silence preceding target & $4.849^{* *}$ & $6.492^{* *}$ & $8.257^{* * *}$ & +1 \\
\hline Silence following probe & 0.000 & $3.408^{*}$ & 0.571 & No \\
\hline Silence preceding target and following probe & $3.237^{* *}$ & 1.726 & 1.511 & No \\
\hline
\end{tabular}

${ }^{*} p<.10 . \quad{ }^{* *} p<.05 . \quad{ }^{* * *} p<.01 . \quad{ }^{* * * *} p<.001$. 
Pure-Tone Distractors and 1-1 Sequences

A

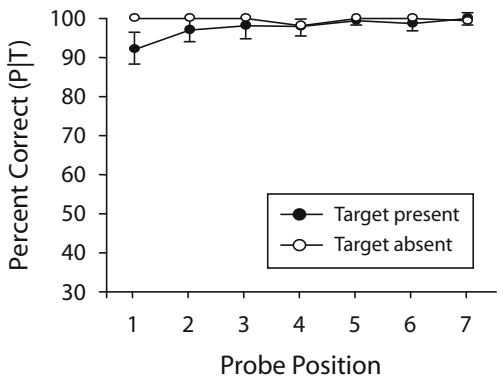

Silence Following the Probe

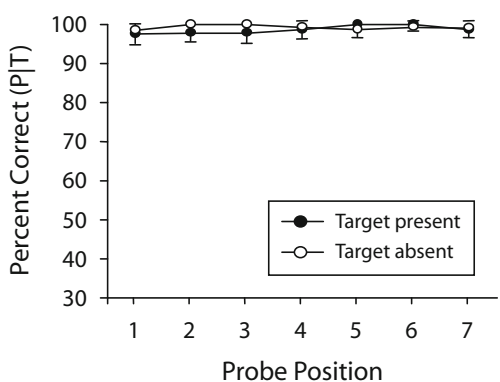

Silence Preceding the Target

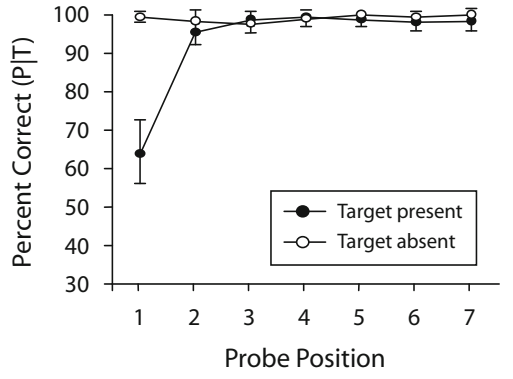

Silence Preceding the Target and Following the Probe

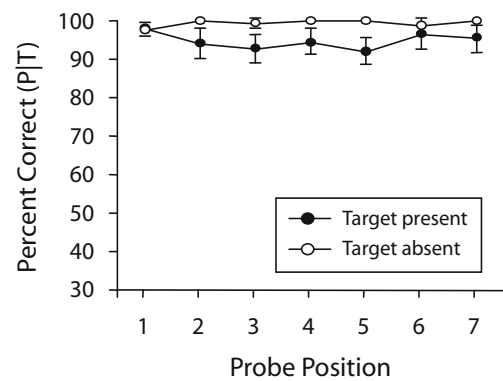

Pure-Tone Distractors and 2-1 Sequences

B

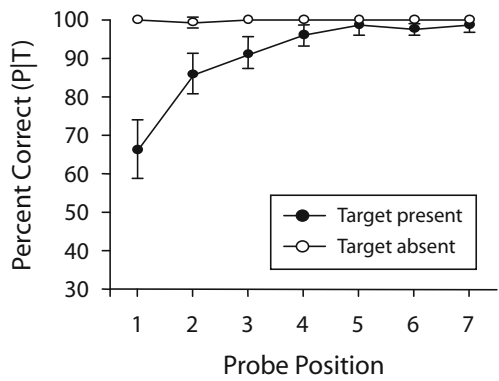

Silence Following the Probe

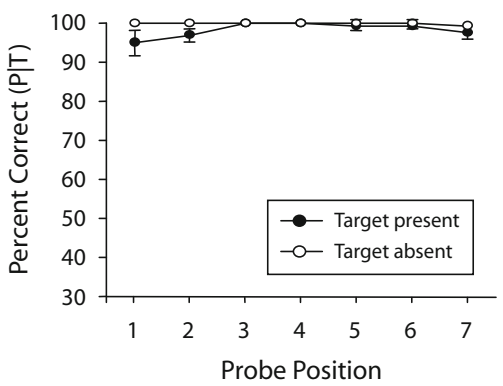

Silence Preceding the Target

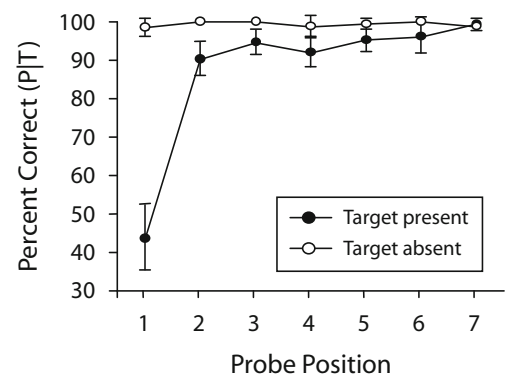

Silence Preceding the Target and Following the Probe

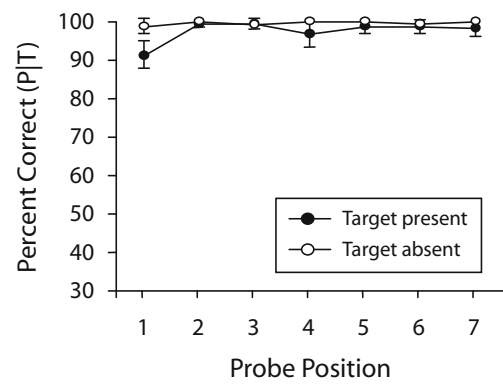

Figure 4. Probe detection accuracy in Experiment 3, as a function of the presence of distractors (full, silence preceding the target, silence following the probe, silence preceding the target and following the probe). Error bars represent 1 standard error. 
Pure-Tone Distractors and 2-2 Sequences

C

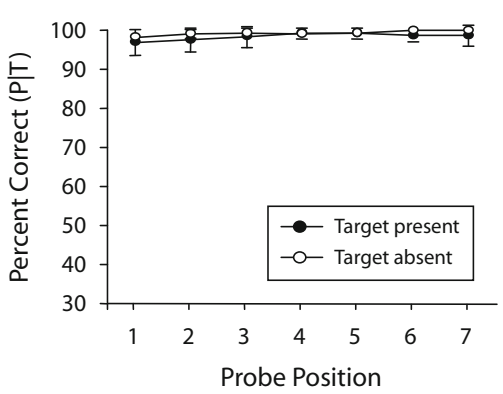

Silence Following the Probe

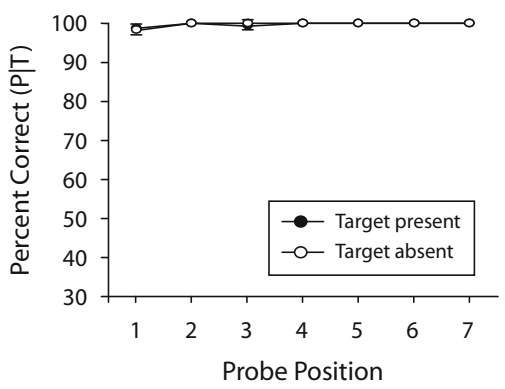

Silence Preceding the Target

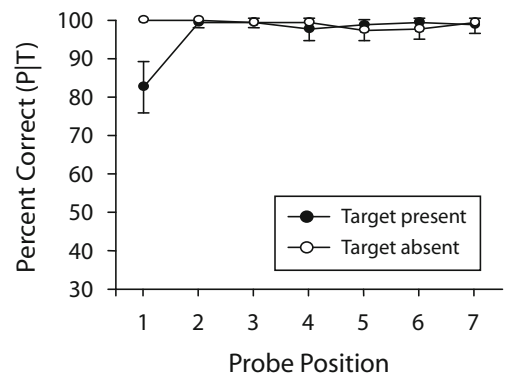

Silence Preceding the Target and Following the Probe

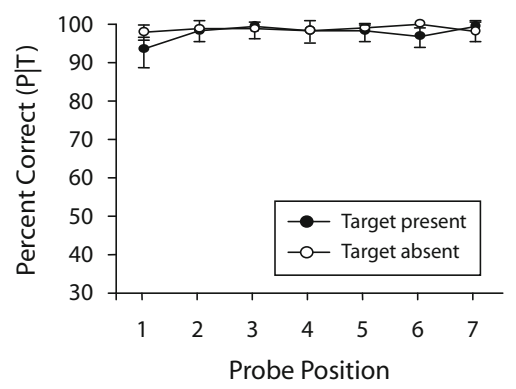

Pure-Tone Distractors and 2-1 Sequences

D

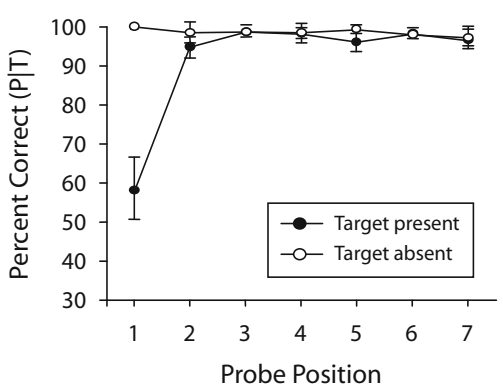

Silence Following the Probe

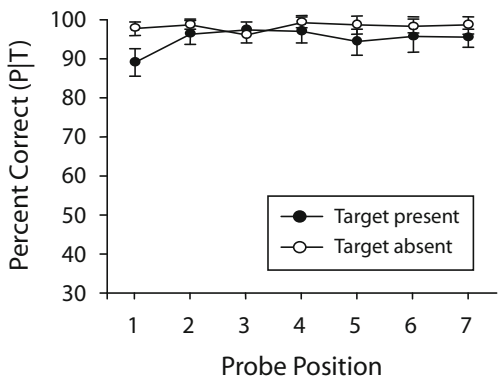

Silence Preceding the Target

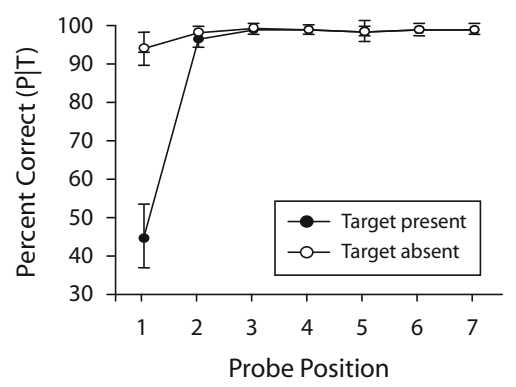

Silence Preceding the Target and Following the Probe

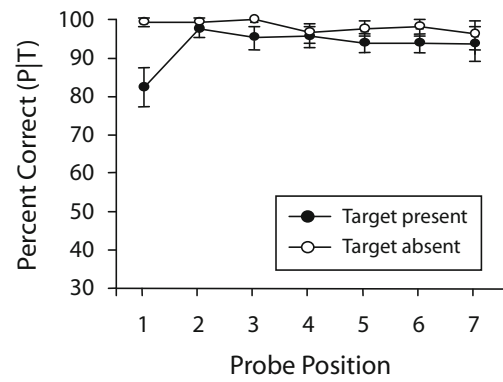

Figure 4 (continued). 
for silence preceding the target sequences, but not for the other two types of sequences. Although there was an overall probe-processing deficit, there was no AB deficit in silence both preceding the target and following probe condition. The definition of AB being used in the present study requires that there be an improvement in probe performance, as a function of its position. As Potter et al. (1998) have suggested, an overall deficit may simply reflect the cost of dividing attention.

The magnitude of the $\mathrm{AB}$ apparent in the silence preceding the target condition was compared with that observed in the full-stream condition using a 2 (stream) $\times 2$ (target presence) $\times 7$ (probe position) within-participants ANOVA. The three-way interaction between stream, target presence, and probe position was significant $[F(6,114)=$ $10.127, p<.001]$. A 2 (stream) $\times 2$ (target presence) within-participants ANOVA at each position revealed an interaction at the +1 position $(p<.01 ; p>.10$ for all other effects). These results indicated that the magnitude of the auditory AB was larger when the distractors preceding the target were replaced by silence.

For the 2-1 sequences, the results revealed a significant $\mathrm{AB}$ for the full-stream distractor sequences and for the silence preceding the target sequences, but showed little evidence for the other two types of sequences. The magnitude of the $\mathrm{AB}$, which was apparent in the silence preceding the target condition, was compared with that observed in the full-stream condition using a 2 (stream) $\times 2$ (target presence) $\times 7$ (probe position) within-participants ANOVA. The three-way interaction between stream, target presence, and probe position was significant $[F(6,114)=$ $5.873, p<.01]$. A 2 (stream) $\times 2$ (target presence) withinparticipants ANOVA at each position revealed an interaction at the +1 position $(p<.01 ; p>.10$ for all other effects). These results indicate that the magnitude of the auditory $\mathrm{AB}$ was increased when the distractors preceding the target were replaced by a silent period.

In summary, the auditory $A B$ was apparent for the $2-1$ and 1-1 sequences, both when a full stream of distractors was presented and when no distractors were presented preceding the target. A 2 (sequence type) $\times 2$ (target presence) $\times$ 7 (probe position) split-plot ANOVA was conducted in order to compare these effects. For full-stream sequences, the three-way interaction between sequence type, target presence, and probe position was significant $[F(6,228)=$ $6.073, p<.01]$. A series of 2 (sequence type) $\times 2$ (target presence) split-plot ANOVAs at each position revealed significant interactions at the $+1,+2$, and +3 positions $(p<$ .05 for the first two; $p=.066$ for the third; $p>.10$ for all other effects). These results indicated that when target and probe were embedded in a full set of distractors, the auditory $\mathrm{AB}$ was larger for the 2-1 sequences than for the 1-1 sequences. In contrast, a complementary analysis of performance when the distractors preceding the target were replaced by silence revealed no significant three-way interaction $[F(6,228)=2.178, p=.128]$.

In Experiment $3 \mathrm{~B}$, for the $2-2$ sequences, there was a significant $\mathrm{AB}$ for the silence preceding the target sequences, but not for the other three types of sequences. It appears that replacing distractors that preceded the target increased the magnitude of the auditory $\mathrm{AB}$ in a pulse distractor sequence as well.

For the 2-1 sequences, there was a significant $\mathrm{AB}$ for the full-stream distractor condition, for the silence preceding the target condition, and for the silences both preceding the target and following the probe condition, but not for the silence following the probe silence. The magnitude of the $A B$, which was apparent in the silence preceding the target condition, was compared with that observed in the full-stream condition using a 2 (stream) $\times 2$ (target presence) $\times 7$ (probe position) within-participants ANOVA. The three-way interaction between stream, target presence, and probe position was not significant $(F<1)$. In addition, 2 (stream) $\times 2$ (target presence) within-participants ANOVAs performed for each temporal position did not reveal any significant interactions ( $p>.10$ for all effects). These results indicate that the magnitude of the auditory AB was not significantly affected when the distractors preceding the target were replaced by a silent period, relative to when a full sequence of distractors was presented.

The magnitude of the AB apparent in the silence preceding the target and following the probe condition was compared with that observed in the full-stream condition, using a 2 (stream) $\times 2$ (target presence) $\times 7$ (probe position) within-participants ANOVA. The three-way interaction between stream, target presence, and probe position was significant $[F(6,114)=6.680, p<.01]$. A $2($ stream $) \times 2$ (target presence) within-participants ANOVA performed for each probe position revealed that there was an interaction at the +1 position $(p<.01 ; p>.10$ for all other effects). Thus, the magnitude of the auditory AB was significantly reduced at the +1 position when no distractors were presented either preceding the target or following the probe, relative to when a full sequence of distractors was presented.

The magnitude of the $\mathrm{AB}$ deficits for the 2-1 and 2-2 sequences when no distractors were presented preceding the target were compared by using a 2 (sequence type) $\times 2$ (target presence) $\times 7$ (probe position) split-plot ANOVA. This analysis revealed that the three-way interaction between target type, target presence, and probe position was significant $[F(6,228)=9.114, p<.01]$. A series of 2 (target type) $\times 2$ (target presence) split-plot ANOVAs at each position revealed a significant interaction at the +1 position $(p<.01 ; p>.10$ for all other effects). These results indicate that the auditory $\mathrm{AB}$ was larger for the 2-1 sequences than for the 2-2 sequences when no distractors were presented preceding the target.

\section{Discussion}

This experiment was conducted in order to examine whether the distractors preceding the target and following the probe have any influence on the magnitude of the auditory AB. For the $2-1$ sequences, as was shown by Shen and Mondor (2006), the distractors following the probe had tremendous effect on the magnitude of the AB. There was a large $\mathrm{AB}$ in the full-stream sequences. However, when the distractors following the probe were replaced by silence, only a small AB was apparent. Similarly, when both the distractors preceding the target and those following the probe were replaced by silence, only a small $\mathrm{AB}$ 
was apparent. This residual $\mathrm{AB}$ could be caused by the passive decay of the probe, as Shen and Mondor argued. These results showed that the overwriting of the probe by the distractors is a major factor in determining the magnitude of the auditory $\mathrm{AB}$ both for pure-tone distractor sequences and for pulse distractor sequences.

Critically, for the 1-1 sequences, whereas there was little evidence of an $\mathrm{AB}$ when a full stream of distractors was presented, a large $\mathrm{AB}$ arose when distractors preceding the target were replaced by silence. Similarly, for the 2-2 sequences, no $\mathrm{AB}$ was apparent when full-stream distractors were presented, but there was a small $\mathrm{AB}$ when the distractors that preceded the target were replaced by silence. Note that even though quite a large $A B$ was apparent for the 2-1 sequences when a full stream of distractors was present, an even larger $\mathrm{AB}$ was generated in Experiment $3 \mathrm{~A}$ when the distractors that preceded the target were replaced by silence. Although it was not significant, there was a trend toward such an effect in Experiment $3 \mathrm{~B}$ as well. These results demonstrated that regardless of the acoustic characteristics of the distractors, relative to the probe processing deficit that was apparent when a full set of distractors was presented, replacing the pretarget distractors with silence either led to an increase in the magnitude of the $\mathrm{AB}$ or generated an $\mathrm{AB}$ where no such deficit had been apparent. This robust result provides strong evidence that the necessity of creating an object file for use in processing the target is a critical determinant of the auditory $\mathrm{AB}$. When no distractors preceded the target, regardless of its relationship to the trailing distractors, creation of an object file was required, and the target processing difficulty was increased. As a result, the increase in time and resources forced a delay in processing the probe. This is consistent with the results that the target detection accuracy was lower when the distractors preceding the target were replaced by silence for the 1-1 sequences. However, the target detection accuracy did not change significantly after deleting pretarget distractors for the 2-2 sequences, and this could be because of a ceiling effect, since the target detection accuracy was always higher than .99 . Although replacing the distractors that preceded the target with silence did not increase the target processing difficulty to the level of changing the target detection accuracy, it could have been enough to increase the duration of the target processing, and the probe processing would be delayed.

In summary, then, the results of Experiments $3 \mathrm{~A}$ and $3 \mathrm{~B}$ provide evidence that the auditory $\mathrm{AB}$ is affected both by a requirement to generate and consolidate an object file for the target and by the overwriting of the probe by the distractors following it.

\section{GENERAL DISCUSSION}

The present study was conducted in order to determine whether object file continuity affects the auditory AB. Although somewhat varied, the results of the present experiments provide clear evidence that this is the case. Before discussing the theoretical implication of our findings, we will first review the principal results obtained in these experiments.

\section{Principal Results}

In Experiment 1, we assessed the effects of attending the target and of the relationship of the target and probe to the distractors within which they were embedded. Probe processing deficits were apparently larger when listeners were required to detect the target than when the target was ignored, and this showed that auditory $\mathrm{AB}$ is not simply a by-product of the masking of the probe by the target (see also Shen \& Mondor, 2006, for similar results). When the target was attended, a larger auditory AB was apparent for the 2-1 sequences (for which the target differed from the distractors in both frequency and timbre, and the probe differed from the distractors in frequency) than for the 1-2 sequences (for which the target differed from the distractors in frequency, and the probe differed from the distractors in both frequency and timbre). To the extent that the processing of a target that is quite different from that of the distractors that precede it requires generation of a new object file, this result certainly raises the possibility that object file creation of the target is important in generating the auditory AB. Of course, the results of Experiment 1 could as easily be attributed to the overwriting of the probe by postprobe distractors; such interference should be greater when the probe is relatively similar to the distractors, as in the $2-1$ sequences, than when it is quite different, as in the 1-2 sequences.

Experiment 2 was conducted, in part, to address these alternative accounts, and it was partly successful in this regard. For the sequences that included pure-tone distractors, there were small $\mathrm{AB}$ deficits, which were paralleled by low target-processing difficulty for both the 1-1 and 2-2 sequences, suggesting that object file creation for the target is important in generating the auditory AB. Otherwise, there would be a large $\mathrm{AB}$ for the 1-1 sequences because of high overwriting of the probe by postprobe distractors. Indeed, the opposite pattern was obtained for those sequences that included pulse distractors, with a large auditory $\mathrm{AB}$ for the $1-1$ sequences, but no $\mathrm{AB}$ at all for the 2-2 sequences. These results could have been caused by the acoustic characteristics of the sounds we used in this experiment. When the distractors were pulses, an object file created for the pulse distractors at the beginning of the sequences included both modulation frequency and carrier frequency components. When the target was attended, for the $2-2$ sequences, a new object file for the pure-tone target derived from the existing object file - that is, incorporating old components, such as carrier frequencywas created, and this required few processing resources. In addition, there was minimal overwriting of the probe by the distractors that followed it, because of their dissimilarity (the probe was a pure tone, and all distractors were modulated). These effects meant that there was very little, if any, impairment in probe perception. Thus, no AB was apparent for these sequences. In contrast, for the 1-1 sequences, significant resources were required for processing the target, because of its similarity to the distractors (both were modulated), even though no new object file needed to be created for it. Moreover, there was a high possibility of the overwriting of the probe by the distractors that followed it, because the probe and the distractors 
were similarly modulated. These effects resulted in a large impairment in probe perception, and, thus, a large $\mathrm{AB}$ was apparent for these sequences. In addition, when the target was ignored, there was no $\mathrm{AB}$ for either type of sequence, and this further proves that sensory masking did not play a role in generating auditory $\mathrm{AB}$.

In Experiment 3, the effect of deleting the distractors that preceded the target and/or followed the probe was examined. The results revealed that for the $2-1$ sequences, there was a large $\mathrm{AB}$ in the full-stream condition, but only a small $\mathrm{AB}$ remained when all postprobe distractors were replaced by silence. Moreover, for the 1-1 sequences in Experiment $3 \mathrm{~A}$ (in which the distractors were pure tones), there was a small $\mathrm{AB}$ in the full-stream condition, but there was a large $\mathrm{AB}$ when all of the distractors that preceded the target were replaced by silence. In Experiment 3B (in which the distractors were pulses), for the 2-2 sequences there was no $\mathrm{AB}$ for full-stream sequences, but there was a significant $\mathrm{AB}$ when all of the distractors that preceded the target were replaced by silence. Thus, the results of Experiments $3 \mathrm{~A}$ and $3 \mathrm{~B}$ provided strong evidence that the postprobe distractors, as well as the effect of the requirement of generating and consolidating the object file for the target, are the primary determinants of the auditory $\mathrm{AB}$ - most likely through overwriting of the memorial representation of the probe.

Taken together, then, the results of the three experiments described here provide strong evidence that the requirement of creating and consolidating an object file for the target and the overwriting of the probe by the postprobe distractors are critically important in producing the auditory $\mathrm{AB}$. Of course, under different environments, one might be more crucial than the other. As the results showed, for pulse distractor sequences, the overwriting of the probe is more dominant than the requirement of creating and consolidating an object file for the target; however, creating and consolidating an object file for the target is more important for pure-tone distractor sequences than for pulse distractor sequences. This explanation is also consistent with the results of visual $\mathrm{AB}$ studies. For example, Raymond (2003) provided evidence that creating an object for the target is a crucial factor in generating the visual $\mathrm{AB}$, but that the relationship of the probe to the distractors did not affect visual $\mathrm{AB}$ when the arrowheads and tridents were used as experimental materials. However, Arnell and Jenkins (2004) showed that probe-distractor similarity was a very important determinant of the visual $\mathrm{AB}$ when letters and digits were presented to the participants.

Below we discuss whether some of the existing theoretical accounts of the visual $\mathrm{AB}$ are consistent with our electrophysiological findings with regard to the auditory $\mathrm{AB}$.

\section{Theoretical Accounts of the Visual AB}

The existing theoretical accounts of the visual $\mathrm{AB}$ can be divided into two types, in accordance with the assumption that each makes with regard to the locus of attention: Early selection models of the visual $\mathrm{AB}$, such as the two-stage detect-then-identify model (Broadbent \& Broadbent, 1987), the attentional gate model (Raymond et al., 1992), and the object file continuity theory (Raymond, 2003) all assume that selection precedes stimulus identification. In contrast, other accounts of the $\mathrm{AB}$, such as the com- petition hypothesis (Shapiro et al., 1994), the two-stage model (Chun \& Potter, 1995), the central interference theory (Jolicœur, 1998), and the object-substitution account (Giesbrecht \& Di Lollo, 1998) are based on the assumption that selection follows stimulus identification.

The two-stage detect-then-identify model (Broadbent \& Broadbent, 1987) consists of, unsurprisingly, two stages. In the first stage, the physical features of every item in an RSVP sequence are encoded in parallel. The second, capacity-limited, stage of processing begins only when a sufficient number of target features have been encoded. The target items (target and probe) are identified in this capacity-limited stage, which is "based on computation of the conjunction of features" (Broadbent \& Broadbent, 1987, p. 112). According to this model, it is the interference in this capacity-limited second stage between processes that are involved in identification of the target and those that are involved in identification of the probe that causes the $\mathrm{AB}$.

According to the attentional gate model (Raymond et al., 1992), target identification includes two stages. In the first stage, a critical feature of the target is detected (e.g., the color white, when participants are required to detect a white letter). In the second stage, the critical feature is linked to an appropriate response, and this leads to identification of the target. To protect the identification process, an attentional gate shuts and locks after detecting the target feature, and this results in an activated inhibition against the processing of new items following the target. This inhibition lasts several hundred milliseconds, and if the probe is presented during this period, its processing will be impaired. In contrast with the two-stage detectthen-identify model (Broadbent \& Broadbent, 1987), the attentional gate model emphasizes the role of an inhibitory process, rather than the effect of interference.

The object file continuity model (Raymond, 2003) posits that the $\mathrm{AB}$ is a direct consequence of a failure to maintain object file continuity. The theory is based on the notion that an object file is created when the first item in a sequence is presented, and that this file is continuously updated as subsequent items are presented. If the target is not perceived as being a new object, updating will be easy, and the existing object file may be maintained. In contrast, if the target is perceived as being a new object, updating will be difficult, and the old object file may be discarded in favor of the generation of a new one. Generating a new object file draws on capacity-limited attentional resources. Therefore, if during this processing the probe is presented, its processing will be impaired because of a scarcity of resources, and an $\mathrm{AB}$ will result.

All three of these early selection models are silent with respect to any effect of postprobe distractors. Given the prominent role that these distractors have been shown to have in the auditory $\mathrm{AB}$, it is clear that without dramatic modification, none provides an adequate explanation of the auditory AB.

One of the late selection models - the competition hypothesis (Shapiro et al., 1994) - is based on the notion that the target and the probe can be processed in parallel in the capacity-limited stage. According to this model, an internal representation that includes both perceptual 
and conceptual characteristics is created for each item in an RSVP sequence, and each such representation is compared with internal templates (based on the target or the probe) that are defined by instructions. If a representation is consistent with a template, the item will be passed into visual short-term memory (VSTM), in which the perceptual and conceptual characteristics of the item are integrated in order to form a unitary representation. This model assumes that responses can be made only to those items that enter VSTM. Aside from the target and the probe, the item immediately following each of them may also be able to enter VSTM because its temporal position is similar to that for the critical items. The competition for limited perceptual and semantic processing resources between the target and the probe and any distractors also in VSTM causes a probe-processing deficit, since the target is typically processed first, because it is presented first. When the probe is presented immediately following the target, the two items have the longest common processing time; the competition between them is the greatest. Thus, the $\mathrm{AB}$ is larger when the SOA between the target and the probe is brief than when the SOA is long. Although this model can explain the effects of the distractors that follow the target, it cannot easily explain the role of the object file continuity that we observed. This model is also inconsistent with previous results that showed that the replacement of the distractor that immediately follows the target does not affect the magnitude of the auditory AB (Mondor, 1998; Shen \& Mondor, 2006). For these reasons, the competition hypothesis (Shapiro et al., 1994) does not appear to provide an adequate account of the auditory $\mathrm{AB}$.

Other late selection accounts, such as the two-stage model (Chun \& Potter, 1995), the central interference theory (Jolicœur, 1998), and the object-substitution account (Giesbrecht \& Di Lollo, 1998), are all based on the idea that two stages are required for processing and reporting the target and the probe successfully. In the first stage, each item in a sequence is identified momentarily. However, in order to successfully report the target and the probe, they must be further consolidated in the second, capacitylimited stage; this consolidation is regarded as being "the process of encoding information into short-term memory" (Jolicœur, 1998, p. 1028). Because of limited capacity, the target and the probe cannot be processed simultaneously in the stage; therefore, processing of the probe is delayed until target processing is complete. During this delay, the representation of the probe can passively decay or be overwritten by the distractors that follow it (Giesbrecht \& Di Lollo, 1998), and this creates a probe-processing deficit. When the time between the target and the probe is brief, the delay in processing the probe is long. Thus, the probe-processing deficit decreases as the time between the target and the probe increases. These models are based on the notion that the items that immediately follow the target and the probe, respectively, have different effects. Whereas the item that immediately follows the target may be processed along with it, thereby increasing the difficulty of target processing and increasing the magnitude of the $\mathrm{AB}$, the item that immediately follows the probe may act to overwrite or replace the representation of the probe in memory, and thereby cause an $\mathrm{AB}$. It seems to us quite likely that, in audition, there is no substantive effect of deleting the +1 item, because it is not processed along with the target (Shen \& Mondor, 2006). Such an interpretation is consistent with the fact that the auditory system generally has better temporal resolution, but poorer spatial resolution, than the visual system.

\section{A Revised Two-Stage Model for Auditory AB}

The results of the present study and of a recent study by Shen and Mondor (2006) appear to be most consistent with a modified two-stage model of the auditory AB that includes recognition that creating an object file for the target plays an important role as well (e.g., Raymond, 2003). Listeners create an object file when the first sound in a sequence is presented, and they continuously update the file when subsequent, similar sounds are presented. This represents the first stage of processing. The target and the probe must be processed in a capacity-limited second stage (i.e., short-term memory consolidation) in order to be successfully reported. However, it appears that if the target is quite different from previous items, then, in general, a new object file must be created and it must enter into the second stage to be consolidated and require a significant amount of processing resources and time; under some circumstances (e.g., a pure-tone target among pulse distractors), the object file for the target composed of old components may require little consolidation in the second stage. In contrast, if the target is not remarkably different from previous items, the object file updating will be easy, and no new file needs to be created, then little second stage processing will be required in general; under some situations (e.g., the target and the distractors are comodulated), the representation of the target may be difficult to be distinguished from those of the distractors, and more resources and processing time in the second stage will be required. Second-stage processing takes time, and processing of the probe will not begin until target processing is complete, because of the limited capacity. During this delay, the representation of the probe sound may be subject to both passive decay and overwriting by the distractor sounds that follow it. In this view, the probe-processing deficit will be greatest when the probe is presented immediately following the target, because the delay is longest. Therefore, the deficit will decrease as the SOA increases.

\section{AUTHOR NOTE}

Correspondence concerning this article should be addressed to D. Shen, Rotman Research Institute, Baycrest Centre for Geriatric Care, 3560 Bathurst Street, Toronto, ON, M6A 2E1 Canada (e-mail: dshen@ rotman-baycrest.on.ca).

\section{REFERENCES}

Allport, [D.] A., \& Hsieh, S. (2001). Task switching: Using RSVP methods to study an experimenter-cued shift of set. In K. [L.] Shapiro (Ed.), The limits of attention: Temporal constraints in human information processing (pp. 36-64). Oxford: Oxford University Press.

Allport, D. A., Styles, E. A., \& Hsieh, S. (1994). Shifting intentional set: Exploring the dynamic control of tasks. In C. Umiltà \& M. Moscovitch (Eds.), Attention and performance XV: Conscious and non- 
conscious information processing (pp. 421-452). Cambridge, MA: MIT Press.

ArNell, K. M., \& JenKIns, R. (2004). Revisiting within-modality and cross-modality attentional blinks: Effects of target-distractor similarity. Perception \& Psychophysics, 66, 1147-1161.

Arnell, K. M., \& Jolicceur, P. (1999). The attentional blink across stimulus modalities: Evidence for central processing limitations. Journal of Experimental Psychology: Human Perception \& Performance, 25, 630-648.

ARnell, K. M., \& LARSon, J. M. (2002). Cross-modality attentional blinks without preparatory task-set switching. Psychonomic Bulletin \& Review, 9, 497-506.

Bregman, A. S. (1993). Auditory scene analysis: Hearing in complex environments. In S. McAdams \& E. Bigand (Eds.), Thinking in sound: The cognitive psychology of human audition (pp. 10-36). Oxford: Clarendon Press.

Brehaut, J. C., Enns, J. T., \& Di Lollo, V. (1999). Visual masking plays two roles in the attentional blink. Perception \& Psychophysics, 61, 1436-1448.

Broadbent, D. E., \& Broadbent, M. H. P. (1987). From detection to identification: Response to multiple targets in rapid serial visual presentation. Perception \& Psychophysics, 42, 105-113.

Chun, M. M., \& PotTer, M. C. (1995). A two-stage model for multiple target detection in rapid serial visual presentation. Journal of Experimental Psychology: Human Perception \& Performance, 21, 109-127.

Chun, M. M., \& Potter, M. C. (2001). The attentional blink and task switching within and across modalities. In K. [L.] Shapiro (Ed.), The limits of attention: Temporal constraints in human information processing (pp. 20-35). Oxford: Oxford University Press.

Duncan, J., Martens, S., \& Ward, R. (1997). Restricted attentional capacity within but not between sensory modalities. Nature, $\mathbf{3 8 7}$, 808-810.

DunCAN, J., WARD, R., \& ShapIRo, K. [L.] (1994). Direct measurement of attentional dwell time in human vision. Nature, 369, 313-315.

Evans, K. K., \& Treisman, A. [M.] (2005). Perception of objects in natural scenes: Is it really attention free? Journal of Experimental Psychology: Human Perception \& Performance, 31, 1476-1492.

Folk, C. L., Leber, A. B., \& Egeth, H. E. (2002). Made you blink! Contingent attentional capture produces a spatial blink. Perception \& Psychophysics, 6, 741-753.

Giesbrecht, B., \& Di Lollo, V. (1998). Beyond the attentional blink: Visual masking by object substitution. Journal of Experimental Psychology: Human Perception \& Performance, 24, 1454-1466.

Hillstrom, A. P., \& Yantis, S. (1994). Visual motion and attentional capture. Perception \& Psychophysics, 55, 399-411.

IsAAK, M. I., ShapIRo, K. L., \& MARTIN, J. (1999). The attentional blink reflects retrieval competition among multiple rapid serial visual presentation items: Tests of an interference model. Journal of Experimental Psychology: Human Perception \& Performance, 25, 1774-1792.

JiANG, Y., \& CHUN, M. M. (2001). The influence of temporal selection on spatial selection and distractor interference: An attentional blink study. Journal of Experimental Psychology: Human Perception \& Performance, 27, 664-679.

JolicEur, P. (1998). Modulation of the attentional blink by on-line response selection: Evidence from speeded and unspeeded Task $\mathrm{deci}_{-}$ sions. Memory \& Cognition, 26, 1014-1032.

Jolicceur, P., \& Dell'ACQua, R. (1998). The demonstration of shortterm consolidation. Cognitive Psychology, 36, 138-202.

Kahneman, D., Treisman, A. [M.], \& GibBs, B. J. (1992). The reviewing of object files: Object-specific integration of information. Cognitive Psychology, 24, 175-219.

Kawahara, J.-I., Di Lollo, V., \& Enns, J. T. (2001). Attentional requirements in visual detection and identification: Evidence from the attentional blink. Journal of Experimental Psychology: Human Perception \& Performance, 27, 969-984.

Kawahara, J.-I., Zuvic, S. M., Enns, J. T., \& Di Lollo, V. (2003) Task switching mediates the attentional blink even without backward masking. Perception \& Psychophysics, 65, 339-351.

Kellie, F. J., \& Shapiro, K. L. (2004). Object file continuity predicts attentional blink magnitude. Perception \& Psychophysics, 66, 692-712.
Maxwell, S. E., \& Delaney, H. D. (2004). Designing experiments and analyzing data: A model comparison perspective (2nd ed.). Mahwah, NJ: Erlbaum.

Mondor, T. A. (1998). A transient processing deficit following selection of an auditory target. Psychonomic Bulletin \& Review, 5, 305-311.

Moore, B. C. J. (2003). An introduction to the psychology of hearing (5th ed.). San Diego: Academic Press.

Moore, B. C. J., \& Jorasz, U. (1992). Detection of changes in modulation depth of a target sound in the presence of other modulated sounds. Journal of the Acoustical Society of America, 91, 1051-1061.

Moore, B. C. J., \& Jorasz, U. (1996). Modulation discrimination interference and comodulation masking release as a function of the number and spectral placement of narrow-band noise modulators. Journal of the Acoustical Society of America, 100, 2373-2381.

Nieumenstein, M. R., Chun, M. M., van der Lubbe, R. H. J., \& Hooge, I. T. C. (2005). Delayed attentional engagement in the attentional blink. Journal of Experimental Psychology: Human Perception \& Performance, 31, 1463-1475.

Olson, I. R., Chun, M. M., \& Anderson, A. K. (2001). Effects of phonological length on the attentional blink for words. Journal of Experimental Psychology: Human Perception \& Performance, 27, 1116-1123.

Potter, M. C., Chun, M. M., Banks, B. S., \& Muckenhoupt, M. (1998). Two attentional deficits in serial target search: The visual attentional blink and an amodal task-switch deficit. Journal of Experimental Psychology: Learning, Memory, \& Cognition, 24, 979-992.

Potter, M. C., Staub, A., \& O'Connor, D. H. (2002). The time course of competition for attention: Attention is initially labile. Journal of Experimental Psychology: Human Perception \& Performance, 28, 1149-1162.

Raymond, J. E. (2003). New objects, not new features, trigger the attentional blink. Psychological Science, 14, 54-59.

Raymond, J. E., Shapiro, K. L., \& Arnell, K. M. (1992). Temporary suppression of visual processing in an RSVP task: An attentional blink? Journal of Experimental Psychology: Human Perception \& Performance, 18, 849-860.

Raymond, J. E., Shapiro, K. L., \& Arnell, K. M. (1995). Similarity determines the attentional blink. Journal of Experimental Psychology: Human Perception \& Performance, 21, 653-662.

Seiffert, A. E., \& Di Lollo, V. (1997). Low-level masking in the attentional blink. Journal of Experimental Psychology: Human Perception \& Performance, 23, 1061-1073.

Shapiro, K. L., Raymond, J. E., \& Arnell, K. M. (1994). Attention to visual pattern information produces the attentional blink in rapid serial visual presentation. Journal of Experimental Psychology: Human Perception \& Performance, 20, 357-371.

SHEN, D., \& Mondor, T. A. (2006). Effect of distractor sounds on the auditory attentional blink. Perception \& Psychophysics, 68, 228-243.

Soto-Faraco, S., \& Spence, C. (2002). Modality-specific auditory and visual temporal processing deficits. Quarterly Journal of Experimental Psychology, 55A, 23-40.

Tremblay, S., Vachon, F., \& Jones, D. M. (2005). Attentional and perceptual sources of the auditory attentional blink. Perception \& Psychophysics, 67, 195-208.

Visser, T. A. W., Bischof, W. F., \& Di Lollo, V. (1999). Attentional switching in spatial and nonspatial domains: Evidence from the attentional blink. Psychological Bulletin, 125, 458-469.

WARD, R., DunCAN, J., \& ShapIRo, K. [L.] (1996). The slow time-course of visual attention. Cognitive Psychology, 30, 79-109.

Yeung, N., \& Monsell, S. (2003). Switching between tasks of unequal familiarity: The role of stimulus-attribute and response-set selection. Journal of Experimental Psychology: Human Perception \& Performance, 29, 455-469.

Yost, W. A. (2000). Fundamentals of hearing: An introduction (4th ed.). San Diego: Academic Press.

Yost, W. A., \& Sheft, S. (1989). Across-critical-band processing of amplitude-modulated tones. Journal of the Acoustical Society of America, 85, 848-857.

Yost, W. A., Sheft, S., \& OpIE, J. (1989). Modulation interference in detection and discrimination of amplitude modulation. Journal of the Acoustical Society of America, 86, 2138-2147. 


\section{APPENDIX}

We conducted a brief experiment in order to evaluate the perceived difference of the pure-tone and pulse sounds used in the study. In this experiment, 14 participants each provided explicit, subjective ratings of 144 pairs of sounds. All of the sounds used in the principal experiments were included in this study, and each sound was paired with itself and with each of the others six times. Within each trial, the two sounds presented were separated by a 1,000-msec silent period. A rating of the difference of the two sounds was made using a scale that ranged from 0 (completely different) to 7 (identical). Responses were made using the keyboard. Trial order was random.

The mean rating for each pair of sounds is described in Table A1. Perceived difference of sounds that differed in both frequency and timbre was significantly higher than for sounds that differed in either carrier frequency or timbre alone ( $p<.01$ for all comparisons). Thus, we found that perceived difference varied precisely as predicted, with differences in both frequency and timbre leading to increases in difference.

Table A1

Mean Rating for Each Pair of Sounds, As a Function of Different Frequencies and Timbres

\begin{tabular}{cc}
\hline Sound Pair & Rating \\
\hline Same Carrier Frequency & \\
Pure-pure & 6.77 \\
Pulse-pulse & 6.82 \\
Pure-pulse & 3.00 \\
250-Hz Difference & \\
Pure-pure & 3.48 \\
Pulse-pulse & 4.18 \\
Pure-pulse & 1.86 \\
500-Hz Difference & \\
Pure-pure & 2.62 \\
Pulse-pulse & 2.80 \\
Pure-pulse & 1.26 \\
\hline
\end{tabular}

Note-A rating of the difference of the two sounds was made using a scale that ranged from 0 (completely different) to 7 (identical).

(Manuscript received October 10, 2006;

revision accepted for publication November 15, 2007.) 